\title{
Arbor
}

\section{Madrid y el Canal de Isabel II}

\author{
Antonio Bonet Correa
}

Arbor CLXXI, 673 (Enero), 39-74 pp.

La construcción del Canal de Isabel II, inaugurado en 1858, vino a solucionar la sed secular de Madrid en la época del estío y a la vez hacer posible el ensanche de la ciudad. La presa del Pontón y la traída de agua del río Lozoya, obras del ingeniero Lucio del Valle, supusieron un avance en la modernización de la capital de España. La creciente necesidad de agua según fue aumentando el índice demográfico de Madrid hizo necesario que se aumentasen las obras del canal con nuevas presas. En 1865 se construyó un Segundo Depósito y en 1915 un Tercer Depósito. También importante tanto desde el punto de vista ingenieril como arquitectónico es el Depósito elevado de la calle de Santa Engracia. A lo largo del siglo XX el canal no ha cesado de ampliar su red y de aplicar nuevas tecnologías para suministrar agua a Madrid.

En la primera mitad del siglo XIX las ciudades más importantes de Europa y de América del Norte conocieron una radical transformación. La Edad contemporánea, impulsada por la idea de progreso, con la revolución industrial y el advenimiento de la burguesía como clase hegemónica, inició en Occidente una nueva etapa histórica. El desarrollo científico, material y cultural de los países más avanzados redundó en la mejora y el auge de la vida urbana. En el año 1851, cuando se celebró la Exposición Universal en Londres, en el diáfano y espacioso Crystal Pala$c e$, de novedosa arquitectura en hierro, las naciones civilizadas pudieron constatar el enorme desarrollo de la industria productora de bienes de consumo en beneficio de los miembros de la clase media, cada vez más numerosa y con mayor poder adquisitivo. Los habitantes de las ciudades adquirieron entonces conciencia del cambio que se operaba en las cos- 
tumbres y el bienestar colectivo. El incremento incesante demográfico, la transformación de la agricultura, la prosperidad económica, el aumento de las comunicaciones y del transporte en común, las mejoras de las condiciones higiénicas y el aumento de los canales y las redes de distribución de las subsistencias, junto con la evolución social y política, prometían un futuro esperanzador para el desarrollo de los pueblos. Aunque con la aparición en el escenario social del proletariado con sus reivindicaciones -no se olvide que El Manifiesto Comunista de Marx-Engels se publicó en 1848-, la burguesía urbana, cada vez más solidificada, se sentía la detentora de un porvenir favorecedor de sus aspiraciones. La renovación interior y el ensanche de las ciudades, la construcción de importantes edificios públicos e institucionales, lo mismo que la modernización de las viviendas y sobre todo la aparición del ferrocarril, incluido el metropolitano, mejorando el transporte entre puntos antes distantes, hicieron que los ciudadanos adquiriesen una nueva mentalidad. El cambio de costumbres y hábitos cotidianos caminaba a la par que la ampliación de los horizontes hasta entonces restringidos a las viejas poblaciones del Antiguo Régimen encerradas dentro de las cercas y murallas que paulatinamente se iban derribando con el triunfo de las ideas liberales. A ello hay que unir acontecimientos que pueden parecer insignificantes ante la magnitud de las Obras Públicas entonces emprendidas por los gobiernos para dotar a las ciudades de las estructuras e infraestructuras necesarias para su modernización. En el orden de lo cotidiano la invención de aparatos domésticos como la máquina de coser Singer ${ }^{\circledR}$ y de artefactos tan prácticos y a la vez lúdicos, como la bicicleta, de la vulcanización de las ruedas Goodyear ${ }^{\circledR}$ para los vehículos todavía de tracción animal supusieron grandes adelantos a los que sucesivamente se fueron añadiendo otros aparatos y utensilios hoy imprescindibles para el hogar y el vivir cotidiano de las gentes.

El pulso político y social del siglo XIX hay que tomarlo en las ciudades. En ellas repercutían los grandes acontecimientos y los conflictos internacionales -las guerras como la de Crimea, de Austria contra Italia y la de Secesión en EE.UU. o las intervenciones coloniales en África del Norte de Francia y España en Marruecos y las de Inglaterra en otros países del mundo-, y las revoluciones internas en las naciones. De estas últimas tuvieron mucha importancia en Europa las que estallaron a la vez en diferentes países, en 1848. En ellas confluyeron el descontento de las clases medias y trabajadoras, los movimientos nacionalistas y las inquietudes de los universitarios y jóvenes artistas e intelectuales. Las contrarrevoluciones y el triunfo de la burguesía ascendente fueron hechos decisivos para establecer un orden democrático y reformista en el 


\section{Madrid y el Canal de Isabel II}

cual todavía el sufragio no era universal. En lo que se refiere a España el triunfo del liberalismo, aunque de la facción moderada, hizo que a mediados del siglo XIX, tras la paz de la primera guerra carlista, pese a las luchas políticas y los pronunciamientos militares, prosperasen los núcleos urbanos más importantes, en especial Madrid, capital de España y Barcelona, emprendedora ciudad industrial e importante puerto del $\mathrm{Me}$ diterráneo.

En el siglo XIX las ciudades occidentales fueron los receptáculos de las innovaciones científicas y tecnológicas a la vez que los motores del progreso material y cultural de las naciones. Verdaderos escenarios de la vida política y de la lucha de clases, tanto las capitales como las poblaciones más dinámicas fueron objeto de atención de los escritores y pintores decimonónicos. Las novelas de Dickens, Balzac, Zola y Galdós retratan, al igual que los artículos de costumbres de Larra y Mesonero Romanos, por citar autores españoles, las transformaciones que sufrieron las ciudades. En sus narraciones y relatos se detecta el lujo y la opulencia de las moradas aristocráticas y burguesas y la miseria de los tugurios que habitaban las clases desposeídas en los barrios bajos y los suburbios de la ciudad. El hacinamiento y la miseria que Gustave Doré nos muestra en un célebre grabado de las casas de un barrio obrero de Londres, es reflejo de la segregación urbana que se producía en la ciudad moderna e industrial. Junto al realismo de estos escritores y pintores hay también que señalar a aquellos que desde propuestas literarias diferentes abordan el tema de la ciudad decimonónica. Las grandes aglomeraciones urbanas crean un nuevo tipo y modelo de ciudad. La concentración del comercio de bienes de consumo -el gran almacén Le Bon Marché fue fundado en 1852-, los lugares de esparcimiento como los teatros, circos y cafés, de cuidada arquitectura y novedosa decoración, eran focos de atracción irresistibles. Las calles de los centros de las ciudades, con sus pomposos edificios, sus anchas aceras plenas de gentes y el intenso e incesante tráfago de vehículos en la calzada, ofrecían en las grandes ciudades un espectáculo inigualable de la vida moderna. En la noche, las avenidas alumbradas con las farolas públicas y las lámparas globo de los escaparates de las tiendas y los establecimientos hacían que su conjunto tuviese una atmósfera mágica. El paseante solitario sentía el palpitar de la ciudad, el latido de la multitud indiferente a su abandono y soledad. Walt Whitman, en Hojas de hierba (1855), y Charles Baudelaire, en Flores del mal (1857), exaltaban la vida moderna. Cautivados por la poesía que emanaban las grandes aglomeraciones urbanas, pronto convertidas en ciudades tentaculares, eran entusiastas de su dinamismo e imparable ímpetu. Fue también entonces cuando Gustave Flaubert, en su novela 


\section{Antonio Bonet Correa}

Madame Bovary (1857), describió la negra ciudad provinciana en la cual una sociedad constreñida por los prejuicios morales está en la antípoda de la urbe moderna. El tema de las ciudades muertas, ancladas en el pasado, los «burgos podridos», la «villahorrenda» de Galdós y la «Vetusta» de Clarín contrastaba con las grandes urbes abiertas al futuro.

Durante la primera mitad del siglo XIX las ciudades españolas, dentro de sus propias coordenadas, tuvieron una evolución, aunque más lenta y no exenta de dificultades, similar a la de los demás países europeos. Es de tener en cuenta que la victoria del liberalismo, de carácter moderado, costó grandes esfuerzos ya que durante el reinado de Fernando VII perduró casi intacta la estructura social y política del Antiguo Régimen. Con la muerte del abominable monarca se produjo la quiebra del poder absoluto y el proceso de modernización del país, no sin repetidos retrocesos. $\mathrm{El}$ atraso económico, en gran parte debido a la Guerra de Independencia, junto con las guerras carlistas, las asonadas y los pronunciamientos militares no facilitaron el desarrollo del país. Con el triunfo de los progresistas, tras la muerte de Fernando VII, en 1833, durante la regencia de María Cristina se dio un paso adelante en la modernización. La reforma administrativa del Ministro Javier de Burgos, que a imitación del modelo francés dividió España en 49 provincias, contribuyó a estructurar el territorio nacional a la vez que sirvió para la distribución y un mejor control de los funcionarios públicos. Durante la mayoría de edad de Isabel II, en la que no faltaron momentos críticos y agitaciones revolucionarias, con la alternancia política de liberales progresistas y de «moderados», se asistió al nacimiento de una nueva economía favorecedora del mundo de los negocios y las finanzas que enriqueció a las clases altas, fomentó la construcción de Obras Públicas como las carreteras y el ferrocarril, se imprimió el primer sello de correos y se instalaron las líneas de telégrafos y contribuyó en cierta medida a impulsar la modernización de las ciudades. Fue en ese momento cuando se construyó el Canal de Isabel II, gracias al cual Madrid pudo saciar su sed secular. La economía dual -Agricultura y Banca y muy escasas empresas fabriles- fue la característica de una España que despertaba a la vida moderna.

El decenio moderado, de 1843 a 1854, es esencial para trazar la línea de demarcación entre el primer tercio del siglo XIX y los acontecimientos posteriores que desembocaron, tras la caída de Isabel II en 1866, en la Restauración monárquica de Alfonso XII que bajo la Regencia de María Cristina duró hasta la mayoría de edad de Alfonso XIII. La figura clave de los moderados fue la del General Ramón María Narváez, el cual pasará a la Historia con el mote popular de «Espadón de Loja». Narváez era el militar partidario del orden más estricto, de la mano dura y la imposi- 


\section{Madrid y el Canal de Isabel II}

ción de la autoridad aunque dentro de cierta normalidad constitucional. En 1844, bajo su mandato como Ministro de la Guerra, se creó la Guardia Civil, cuyo papel fue fundamental como garante del orden en todo el territorio nacional. Figura contrapuesta a la suya, dentro de la política moderada, es la de Juan Bravo Murillo, jurista que tenía como lema «legalidad y economías» y que despectivamente en su época le llamaban «el Abogado». Auténtico tecnócrata, Bravo Murillo es hoy admirado por su política en pro de las Obras Públicas, sus reformas administrativas como la ley de Funcionarios, el Concordato firmado con la Santa Sede y también por los Opúsculos que escribió tras retirarse de la política activa en 1858. Según Alfredo Opisso, en su libro Semblanzas de políticos del siglo XIX (Barcelona, 1908), "fue un grande, un verdadero, un incomparable estadista, tal vez el único que hayamos tenido en todo el transcurso del pasado siglo». Para Fraga Iribarne la personalidad y las ideas de Bravo Murillo sólo son comparables a las de Cánovas del Castillo. Para el historiador José Luis Comellas, estudioso de La política y administración en la España isabelina (1972), los planes del ministro decimonónico sobre caminos, canales, puertos y minas, incluido el de la construcción del Canal de Isabel II, se anticipan a su tiempo, de tal manera que «muchas de las realizaciones del siglo XX han estado basadas o inspiradas en los planes de gobierno de Bravo Murillo». Hombre que tenía algo de gris y opaco, de burócrata civil y austero, su figura es esencial y paradigmática de una época tan crucial para España.

Sin la acción política y administrativa de fomento de las Obras Públicas, impulsada por ministros de la talla de Bravo Murillo y la existencia del cuerpo estatal y especializado de los ingenieros de Caminos, Canales y Puertos, no se puede comprender el avance que se produjo en España a mediados del siglo XIX. El deseo de las minorías más cultas y responsables era el poder recuperar el retraso histórico y económico que padecía el país. El ingeniero Lucio del Valle, constructor del tramo de las Cabrillas, en la carretera Madrid-Valencia, del Canal de Isabel II y Director de las obras de reforma de la Puerta del Sol en Madrid, además de otros importantes trabajos de ingeniería, en una memoria publicada en 1849, con el título Reflexiones acerca del impuesto de portazgos, opinaba que «terminadas felizmente las disensiones civiles, se ve con satisfacción llegada ya la época de ocuparse muy poco de las cuestiones políticas y dar la justa preferencia a las que tienen por objeto el aumento de nuestra riqueza». Todo un programa que en manos tan expertas como las suyas y las de otros distinguidos ingenieros hacía posible el llevarlo a cabo de acuerdo con las posibilidades, en parte limitadas, de las que disponía el Estado. Ni los cambios políticos ni los acontecimientos más desfavorables 
fueron capaces de frenar la marcha de las obras que paulatinamente y sin fallos importantes, fueron dando una nueva faz al territorio y a las principales ciudades españolas.

Los años de mediados del siglo XIX, según el escritor y novelista Pedro Antonio de Alarcón, coetáneo de los hechos que narramos, fueron en España los de la «Edad de Oro de las Obras Públicas». La construcción de carreteras, ferrocarriles, viaductos, presas, canales, puertos, faros y demás fábricas de utilidad pública fue incesante. Sus autores, los ingenieros, pasaron a ser héroes de una nueva sociedad. En las novelas, el personaje que representa las ideas progresistas es siempre un ingeniero. Oficialmente las autoridades eran conscientes de la importancia que para la administración tenía la existencia de un cuerpo disciplinado de especialistas capaz de realizar grandes obras. En 1856 don Cipriano Segundo Montesinos, Ministro de Fomento, en la Memoria sobre el estado de las Obras Públicas en España, afirmaba que la publicaba con el «deseo de que se conozca el progreso sucesivo que ha tenido este interesante ramo de la Administración: cuál fue su pasado, cuál su presente y lo que puede ser su futuro». Un año antes, en 1855, tras el pronunciamiento que trajo el bienio progresista, el ingeniero Arturo Marcoartu, en un artículo publicado en la Revista de Obras Públicas, titulado "La Revolución y las Obras Públicas», con un engolado estilo retórico, a propósito del proyecto de ferrocarril Madrid-Lisboa, afirmaba que los españoles debían felicitarse «porque el sol que se eleva sobre nuestro horizonte es de paz, ventura y libertad; como ingenieros, porque con el progreso de las ideas se engendra el vapor y nace la electricidad; como soldados del ejército de la paz y de la civilización». En su opinión los pueblos por medio de las líneas férreas se unirían. En el caso de España y Portugal a las que «bañan los mismos ríos y tienen las mismas costas» el ferrocarril sería un vínculo estrecho. El sueño del progreso y de la paz universal unido a la actividad científica y técnica era, desde Saint-Simon y los positivistas, un ideal que estimulaba la mente de los ingenieros, orgullosos «de los descubrimientos y las conquistas» del siglo XIX. En el editorial del primer número de la Revista de Obras Públicas -que fundada en 1853 fue, y sigue siendo, el órgano de expresión de los ingenieros de Caminos, Canales y Puertos-, se afirmaba que nadie desconocía que las Obras Públicas, auxiliares de la civilización después de la prensa, eran el principal agente del progreso, abriendo nuevos horizontes al porvenir.

La contribución de los ingenieros al desarrollo material del territorio y a la ordenación y construcción de la ciudad moderna a lo largo del siglo XIX fue enorme en todos los países de Europa. En España los ingenieros cumplieron perfectamente el papel que se les asignó. Las sucesivas pro- 
mociones salidas de la Escuela de Caminos a partir de su reapertura en 1834, tras haber sido cerrada durante años por Fernando Vll, proporcionaron al Estado español un disciplinado cuerpo civil capaz de llevar a buen término las empresas que se le encomendaban. Con una sólida formación científica, los ingenieros eran profesionales modernos y al día, que sabían idiomas y viajaban al extranjero con el fin de introducir en España los adelantos del siglo. En el libro Apuntes sobre los objetos correspondientes al Ramo de las Obras Públicas presentados en la Exposición Universal de París de 1855, escrito por Lucio del Valle, Ramón Echevarría y Andrés de Mendizábal, se enumeran y valoran los trabajos llevados a cabo por los ingenieros extranjeros en sus respectivos países, no sólo se ponderan las grandes obras - presas, canales, carreteras, puentes, faros, etc.- que modifican la naturaleza sino también se señalan otras en apariencia menos importantes de índole urbana: «los ensanches de calles y plazuelas, los abastecimientos de aguas potables, las alcantarillas, el alumbrado, los ferrocarriles subterráneos para el servicio público interior» que mejoran las ciudades y que se ejecutan «en tanto número y en una escala que jamás en otra época alcanzaron». La cita anterior es muestra de cómo las Exposiciones Universales fueron el escaparate y el índice de progreso que se estaba llevando a cabo en las naciones civilizadas y en especial en las grandes ciudades. Los ingenieros, a lo largo del siglo XIX fueron verdaderos constructores de las urbes metropolitanas. Tanto en los demás países europeos como en España los ingenieros fueron los encargados del trazado vial y de la dotación de infraestructuras de las poblaciones. Después de la polémica que con motivo de la publicación de la Real Orden de 10 de octubre de 1845, titulada Instrucción para promover y ejecutar las Obras Públicas, se entabló entre los arquitectos y los ingenieros, ya que los primeros consideraban que esta disposición administrativa lesionaba atribuciones en el ramo de la construcción, se llegó a una distribución de tareas de ambas profesiones. No es cuestión aquí de tratar esta ardua cuestión de competencias profesionales. Solamente señalemos que tras los trabajos de la «Comisión de deslinde de atribuciones», en la cual intervino en 1855 el ingeniero, y también arquitecto, Lucio del Valle, quedaron oficialmente delimitadas las áreas de trabajo de una y otra profesión. A los arquitectos en tanto que componentes de una profesión liberal se les asignaba la construcción de edificios y obras de encargo de particulares mientras a los ingenieros las obras estatales. Entre estas últimas figuraban las de urbanismo: el trazado vial y las infraestructuras de servicios y saneamiento. El resultado de esta decisión administrativa dio sus frutos. Los ensanches de las ciudades españolas, Barcelona y Madrid en 1860 y de Bilbao en 1873, por ci- 
tar las tres más notables, fueron obra de ingenieros de caminos. Como colofón y broche de oro en pro de la ciudad moderna subrayemos que el ingeniero de Caminos Ildefonso Cerdá no sólo fue autor del Ensanche de Barcelona sino también un gran teórico. La palabra urbanismo, hoy admitida universalmente, la empleó Cerdá por primera vez. Su libro Teoría general de urbanización y aplicación de sus principios y doctrinas a la reforma y ensanche de Barcelona, publicado en Madrid en 1858, es un libro fundacional de un nuevo saber, la biblia del urbanista. La ciudad decimonónica de la era industrial era, pues, el objeto del análisis y la actividad creadora de los ingenieros.

A mediados del siglo XIX los viajeros extranjeros advirtieron la transformación que se estaba operando en la sociedad urbana española, ansiosa de modernidad. Las clases altas, dadas al incipiente capitalismo, a los negocios de banca y bolsa, al agio más que al fomento de la industria y las empresas productivas, aspiraba a vivir a la europea. Las clases medias seguían la moda como podían con los escasos recursos con los que contaban. En 1857 el francés Edgar Quinet, que había visitado España en 1843, al publicar, en 1857, el relato de Mes vacances en Espagne, apunta que ha encontrado bastantes cambios: «el miriñaque ha desplazado completamente la antigua saya, tan bonita e inmoral. La gente se preocupa por la bolsa y se han abierto ferrocarriles. Ya casi no hay bandidos ni gitanos». Otro tanto advierte Prosper Mérimée, el famoso autor de Carmen. En una carta a uno de sus amigos parisienses, en su séptimo y último viaje a España, en1864, le escribe: «He encontrado Madrid muy cambiado, muy mejorado desde el punto de vista de la civilización, pero privado del carácter original de antaño. Las mujeres no llevan mantilla...». En otra carta otro amigo le informa: «He encontrado a Madrid muy cambiado desde mi última visita, con muchos edificios nuevos, mejor construidos que los anteriores. Pero el mayor cambio consiste fundamentalmente en la abundancia de agua, de la que la ciudad carecía tanto como Cannes anteriormente. Están plantando árboles, haciendo plazas y todo ello va muy bien Lo poco que quedaba del atuendo nacional ha desaparecido. Las señoras visten como en París, quizás un poco más ridículas, con trajes largos con los que van barriendo el sucísimo pavimento. Algunas siguen usando mantilla...». Indudablemente Mérimée registra dos hechos fundamentales para Madrid como son la traída de aguas del Lozoya por medio del Canal de Isabel II y el inicio de las obras de reforma interna y de ensanche de la capital de España. A partir de esta fecha se puede decir que finalizó el viaje romántico por Espagne et le Maroc de los franceses aunque siempre siguieron encontrando que la áspera y apasionante España les seguía proporcionando fuertes emociones estéticas. 
«Oh Madrid! ¡Oh Corte! ¡Oh confusión y regocijo de las Españas!». De esta manera comenzaba una conferencia de don Benito Pérez Galdós, leída en 1915 por don Serafín Álvarez Quintero en el Ateneo, en la cual el gran novelista evocaba la rancia capital de España cuando, en 1862, llegó de Canarias para estudiar la carrera de Derecho en la Universidad Central. La Villa y Corte era todavía la ciudad que habían descrito Larra y Mesonero Romanos, una especie de poblachón manchego y lugar histórico, pero en trance de cambiar. El punto de inflexión del Madrid moderno se iniciaba precisamente entonces. La construcción de nuevos edificios como el Congreso de los Diputados, de 1842 a 1850, del Palacio del banquero Marqués de Salamanca, de 1855 a 1858, de la Casa de la Moneda, en 1856, y el inicio de las obras de la Biblioteca Nacional, en 1862, marcaban la pauta de lo que entonces se empezaba a llamar «Madrid moderno». La reforma de la Puerta del Sol, en 1859, de la cual son interesantísimas las fotografías que hizo el inglés Charles Clifford de los viejos edificios que fueron derribados para dar lugar al nuevo corazón de $\mathrm{Ma}$ drid, fue, con otras intervenciones puntuales en el centro de la ciudad, decisiva para la transformación del casco histórico. No se diga ya las obras del Ensanche, aprobadas en 1860. Galdós a lo largo de su vida, que transcurrió hasta su muerte en Madrid a principios del siglo XX, fue un testigo del cambio radical de una ciudad que a partir de 1874, durante la Restauración, vio la construcción de importantes edificios institucionales, bancos, palacetes y magníficas casas burguesas y adquirió un aire de gran capital monárquica para convertirse, a principios del siglo $\mathrm{XX}$, en una metrópoli moderna. Sólo los viejos barrios castizos, con sus Corralas, conservaron su aspecto tradicional, objeto de la curiosidad literaria de los libretistas de zarzuelas y los autores de piezas cómicas y sainetes.

Desde finales del siglo XVIII hasta mediados del siglo XIX Madrid tuvo dos problemas urbanos: la creciente escasez de espacio para construir nuevas viviendas y el insuficiente abastecimiento de aguas para el consumo de los habitantes durante la estación estival. Ambas cuestiones se resolvieron bajo el reinado de Isabel II. Respecto a los inmuebles de habitación hay que recordar que en 1833 Larra, en su artículo «Las casas nuevas», critica las viviendas que se construían entonces «de la noche para la mañana» y «con más balcones que ladrillos y más pisos que balcones». Aparte de ser "monótonamente uniformes a causa de la estrechez de sus interiores, obligaban a las familias a alojarse en sotabancos, entreplantas y guardillas, apiñadas de tal manera que si viajasen en una diligencia, de pie y empaquetados dentro de un baúl, alejándose de $\mathrm{Ma}$ drid, no por puertas, sino por arriba, como se marcha el chocolate de una chocolatera olvidada sobre las brasas». La imagen no puede ser más ex- 


\section{Antonio Bonet Correa}

presiva. Ante tal panorama se comprende que urgiese resolver tan vital problema. Momentáneamente se encontró una solución a la demanda de habitaciones gracias a la desamortización eclesiástica, construyéndose en los solares que habían quedado vacíos de los edificios y las huertas de los antiguos conventos. Don Ramón Mesonero Romanos, que en tanto que concejal del Ayuntamiento de Madrid se ocupó de las mejoras del centro urbano, no veía que fuese necesario el aumento de la ciudad fuera de la antigua cerca que desde el siglo XVII había delimitado el contorno de la capital de España. Pensaba que con ocupar los solares de los viejos conventos y sus huertas que habían quedado libres en 1835 a causa de la desamortización eclesiástica de Mendizábal, se podía resolver la falta de espacio para la construcción de nuevas viviendas. Su visión, míope y de pequeño burgués, le impedía darse cuenta de que, con ello, se colmataba el centro, privándole de los espacios abiertos de los pensiles o vergeles de las clausuras del pasado, que junto con los jardines privados y patios de los palacios nobles, hacían que la ciudad fuese más higiénica y agradable para sus habitantes. A tan conservador criterio se opuso el de los partidarios a ultranza de expandir la ciudad creando nuevos barrios. El anteproyecto de Ensanche de Madrid, del ingeniero Carlos María de Castro, aprobado en 1860, vino a resolver por fin el problema. La construcción de barrios como el de Salamanca constituye hoy, con su planta regular de calles rectas y anchas, un testimonio de lo acertado que fue el moderno Ensanche. Galdós, en el Episodio Nacional titulado Montes de Oca, hace hablar a un personaje del año 1840 de la siguiente forma: «No ha de pasar mucho tiempo sin que vea Usted construir un Madrid con casas magníficas... casas como no se han conocido aquí nunca, con portales a modo de palacio y comodidades por dentro y decorado muy bonito». Aún faltaban más de veinte años para que el sueño de algunos madrileños se llevase a cabo. En 1840 Madrid todavía era una ciudad de estrechas calles mal alumbradas y con pésimo pavimento. En el mismo Episodio se puede leer en boca de una señora: «¿Y Usted no ha oído decir que van a poner una cosa que se llama el gas, para alumbrar toditas las calles?»; la ciudad de los románticos estaba necesitada de una renovación y una expansión urbana que muchos ciudadanos reclamaban.

El otro problema que a mediados del siglo XIX tenía que resolver Madrid era la perentoria necesidad de aguas para el consumo de sus habitantes. Durante siglos la Villa y Corte había estado abastecida por los célebres «viajes de agua». Desde la fundación de Madrid, en el siglo IX, por Mohamed I hasta 1858, en que se inauguró el Canal de Isabel II, la capital de España bebió las aguas subterráneas que, por medio de minas, pozos y galerías, surtían las numerosas fuentes públicas dispersas en los 


\section{Madrid y el Canal de Isabel II}

distintos barrios de la ciudad. Al igual que en Marrakech y Teherán, Madrid contó con este singular sistema de origen oriental. En 1850, año en el cual ya estaban en marcha las obras del Canal de Isabel II, Pedro Felipe Monlau, en el libro Madrid en la mano o El amigo del forastero en Madrid y sus cercanías, todavía abogaba por mejorar y ampliar los viajes de agua: «Deseamos el mayor acierto en la resolución de este trascendental negocio, para que nunca llegue el caso de encontrarse Madrid con una obra de inmenso costo que no dé resultado alguno útil. Si no tanto escasea el agua para la bebida, como para la limpieza, el riego, las industrias, etc., quizás fuera preferible y menos expuesto emplear en la construcción de aljibes y pozo-fuentes, norias y pozos, y en el alumbramiento de las aguas subterráneas en general, lo que se piensa en invertir en la traída de aguas del Lozoya». Pero como muy bien reconocía Mesonero Romanos, en su Nuevo Manual de Madrid, publicado en 1854, para transformar «en abundancia la penuria secular de esta población en tan importante elemento de vialidad y riqueza», era «de urgencia disponer la conveniente canalización para la distribución del copioso raudal que nos promete el Lozoya para el año próximo, a fin de que llegadas las aguas a las afueras de Madrid, no tarden sus habitantes en recibir y tocar sus inmensos beneficios». Incluso el siempre crítico Ángel Fernández de los Ríos, autor del utópico, pero interesante, libro El futuro Madrid, paseos mentales por la capital de España tal cual es y tal cual debe dejarla transformada la revolución (1868) y de una posterior y muy completa Guía de Madrid (1876), reconocía los grandes beneficios que a Madrid había aportado el Canal del Lozoya. Al hacer la historia de la escasez de agua que «apretaba de día en día» a la capital, recuerda los proyectos que, desde Carlos III hasta la construcción del Canal de Isabel II, se sucedieron sin éxito: en 1765, el del coronel de ingenieros Jorge Sicre y Béjar, en 1786 del arquitecto Juan de Villanueva, en 1819 el del matemático Mariano Vallejo, en 1822 del ingeniero José Coquerel y en 1829 el de Francisco Javier Barra. La confusión era tan grande que llegó a pensarse que Madrid nunca llegaría a poder saciar su sed secular. Fueron por fin los ingenieros Juan Rafo y Juan de Ribera quienes comisionados para analizar el antiguo proyecto de Barra adaptado con algunas modificaciones por el ingeniero Pedro Cortijo, proporcionaron la solución. Abandonando la idea de traer a Madrid agua de los ríos Jarama, Guadalix y Manzanares, optaron por ir a buscar el caudal más lejos, en plena sierra, al río Lozoya. Aprobado en 1851 el proyecto, se procedió a la ejecución de las obras, que duraron hasta 1858 , año en el cual, con gran alborozo de los madrileños, llegó el agua en tal abundancia que el proyecto, cuya realización según un personaje de Galdós en el Episodio 


\section{Antonio Bonet Correa}

Nacional Narváez a las gentes les parecía «un cuento de hadas», fue una feliz realidad.

Hasta la inauguración del Canal de Isabel II los madrileños tenían que aprovisionarse en las fuentes públicas. En torno a ellas se reunían a diario los criados y las criadas de servicio de las casas y los aguadores. Famosos en Madrid fueron los grupos variopintos que, en el Siglo de Oro, acudían a la Fuente de la Mariblanca, en la Puerta del Sol. En la época romántica, los aguadores, recios y robustos mocetones originarios de Asturias y Galicia, fueron retratados por artistas como Alenza y los ilustradores de los artículos de costumbres. Antonio Flores, en 1851, publicó, en el Semanario Pintoresco, un texto titulado «Los Aguadores. El de Cuatro Arrobas y el de Cuatro Cartillas», haciendo la diferencia entre los que portaban el agua a las casas, subiendo a los pisos cargados con pesadas barricas o cubas y aquellos que en las calles y plazas de la ciudad vendían el agua en los vasos que llevaba en una cesta. En el cuadro Tipos madrileños en la Puerta del Sol de Ramón Cortés (Madrid, 1855) se ve en primer plano a una aguadora con un pequeño artilugio portátil con los adminículos de su oficio está a la espera de un cliente. El oficio de aguador estaba reglamentado de forma que tenían que comprar la licencia al Ayuntamiento. Hasta bastante entrado el siglo XX perduraron los aguadores que, en épocas de sequía o en los pisos altos de las casas en las que no había la suficiente presión, solícitamente seguían ofreciendo sus buenos servicios.

La construcción del Canal fue, sin duda alguna, un hecho trascendental para Madrid. Los habitantes de la ciudad fueron conscientes del gran adelanto que suponía tener agua corriente a domicilio, aunque, en un principio, muchas casas tenían solamente una fuente en el patio y los vecinos tenían que bajar a recogerla en pequeños recipientes. Mesonero Romanos, que consideraba de vital importancia la llegada a la Villa y Corte del «abundoso caudal de aguas del Lozoya», lo comparaba a la red de ferrocarril que unía Madrid con «las playas del Mediterráneo». Ambas realizaciones eran, a sus ojos, «sucesos decisivos» que habían cambiado las condiciones de vida de los madrileños. Desde el punto de vista la obra fue valorada como una empresa costosa y necesaria. Los textos de los Reales Decretos, firmados por Juan Bravo Murillo, Presidente del Consejo de Ministros, no pueden ser más expresivos. El 18 de junio de 1851, afirma que «Madrid ve amenazada su existencia por la escasez de agua y que el gobierno no puede permanecer por más tiempo mero espectador de los sufrimientos actuales de los habitantes, ni aguardar con indiferencia las calamidades que amargan a una numerosa población que crece rápidamente». El 22 de junio del mismo año comunica que «convencida S.M. la Reina, mi augusta ama y señora de la necesidad apremiante de proveer 


\section{Madrid y el Canal de Isabel II}

a esta capital de aguas que hoy tiene» ha ordenado se construya el Canal que tan necesario era para solucionar la carestía de agua de la ciudad. Otro tanto se dijo cuando se concedió a una empresa particular, finalmente sustituida por el Ministerio de Fomento, la conducción de aguas a Madrid. Con términos muy explícitos se señalaba que el agua era para la capital de España un «indispensable elemento de existencia, de riqueza y comodidad». Desde el punto de vista de la ingeniería se pueden citar textos que recalcan lo gigantesco del esfuerzo que suponía llevar a cabo una obra de la envergadura del Canal de Isabel II. El ingeniero que dirigió las obras, Lucio del Valle, en su Memoria sobre las filtraciones del Lozoya cerca de la Presa del Pontón de la Oliva y medios empleados para cortarlas (1857), tras una serie de disquisiciones acerca del poder, del tiempo y del dinero que, en general, requería la realización de las construcciones ingenieriles, en las cuales el sello del saber y el triunfo de la ciencia quedaban perpetuados, concluía que eran «obras colosales que constituyen con sobrada justicia el orgullo de los tiempos modernos».

Las grandes empresas requieren grandes determinaciones. Sin el empeño de Bravo Murillo y la gran pericia y el saber de los ingenieros es-

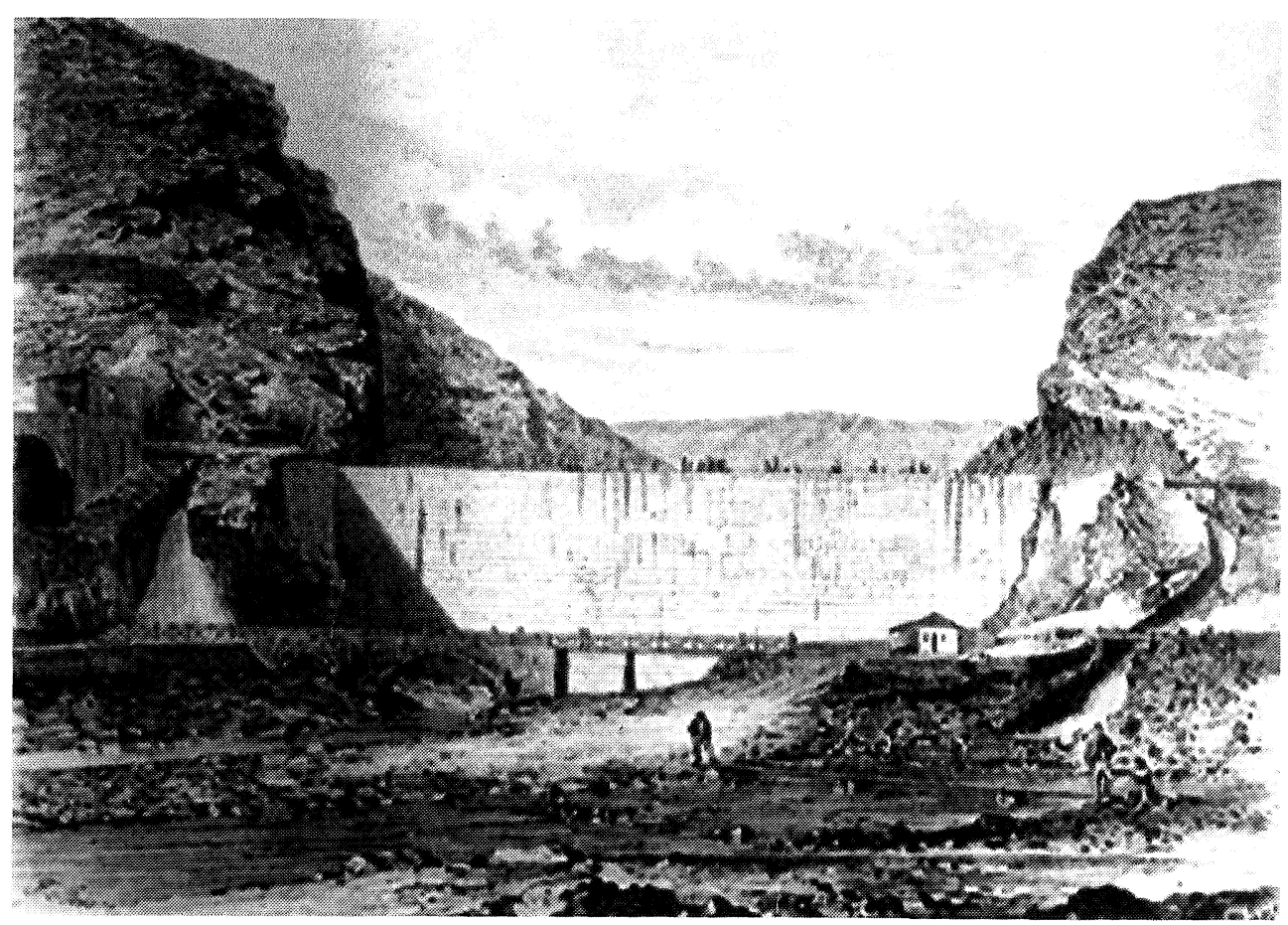

Vista de la presa del Lozoya en 1857. Colección Casariego (Museo Municipal de Madrid) 
pañoles de la época hubiera sido difícil realizar tamaña hazaña. La admiración que producen al espectador las presas, los acueductos, sifones, las almenaras y demás obras de fábrica del Canal, cuando se contemplan en pleno paisaje de la Sierra se debe a la monumentalidad y gran escala de sus construcciones. Las dos primeras presas, la del Pontón de la Oliva, de 1851-1858, hoy fuera de servicio, pero que se conserva perfectamente, o la de El Villar, de 1873-1882, la primera presa de arco de gravedad que se construyó en Europa, obra que se adelantó treinta años a las que más tarde se construirían en todo el mundo de su tipo, no sólo tienen valor histórico sino también resultan impresionantes por su poder de modificación de la naturaleza. Otro tanto sucede con las más modernas como la de Puentes Viejas, de 1925 y recrecida en 1939, El Vado, de 1960, o la de El Atazar, de 1972, la presa más importante del sistema de abastecimiento a la Comunidad de Madrid.

Los amplios panoramas y las construcciones merecen ser conocidos de todos los madrileños. En la Memoria sobre el Estado de los diferentes servicios en 1911 del Canal de Isabel II, don Ramón Aguinaga, su entonces Ingeniero-Director, iniciaba el texto informativo diciendo: «En nuestra época de tourisme (sic) y de sport, no es difícil el tropezar con madrileños que han visitado los fijords (sic) de Noruega, los lagos suizos e italianos, la Costa Azul o los embalses del Nilo, siendo, sin embargo, mucho más escaso el número de aquellos que han explorado el curso del Canal de Isabel, que con 76 kilómetros de recorrido trae a Madrid el agua de sus viviendas y de sus calles». El interés por la arqueología industrial y la ingeniería moderna son los máximos alicientes para emprender el viaje, más bien la excursión montañera, de los amantes de la naturaleza y de las construcciones hidráulicas de carácter a la vez útil de gran belleza estética.

La puesta en marcha de una empresa de la categoría y magnitud del Canal de Isabel II requería una organización financiera, científica y técnica de gran precisión y eficacia. Un período, tan de luces y sombras como fue el reinado de Isabel II, contó, sin embargo, con hombres cuya voluntad era modernizar España. También que tenían la capacidad para ello. El historiador José María Jover, en el tomo XXXIV de la Historia de España, fundada por Menéndez Pidal, asevera que durante el reinado de Isabel II «la incorporación de España a un ritmo histórico y a unas formas políticas acordes con las de su entorno europeo significa un irresistible salto adelante; significa, verdaderamente, el advenimiento de la España Contemporánea». El Canal de Isabel II, que hizo que Madrid contase, a mediados de siglo, con el más adelantado sistema de abastecimiento de agua de Europa, es una obra pública que pone muy alto el listón de la capacidad de los ingenieros y de la administración española 
en la materia. El Presidente del Consejo de Ministros, el probo y diligente jurista y tecnócrata Juan Bravo Murillo, con su buen sentido de la organización, supo no sólo procurar los medios necesarios sino también elegir a las personas que llevarían a buen término la obra. Para la financiación se abrió una suscripción pública que rentaría según el capital aportado. La reina fue la primera que encabezó la lista de suscriptores: Para la ejecución de los trabajos formó un Consejo de Administración y un director de las obras. El primer Director fue el Ingeniero José García Otero al que sucedió en el cargo, en 1855, Lucio del Valle, el cual desde el inicio fue el cerebro rector del Canal y quien, en realidad, dirigió los trabajos a pie de obra. Los nombres de Juan Rafo y Juan de Ribera, Eugenio Barron, Constantino de Ardanaz, José Morer, Alejandro Millán y Mariano Cervigón, cada uno desde sus respectivos puestos y en su debido tiempo y tarea, constituyeron el elenco de acreditados profesionales que respectivamente realizaron la cartografía y las nivelaciones para establecer los planos topográficos, los desmontes y el diseño de los proyectos: la presa del Pontón de la Oliva, la embocadura del canal y sus conducciones, puentes, acueductos, sifones, almenaras y partidor de aguas, además de otras construcciones y elementos de arquitectura hidráulica.

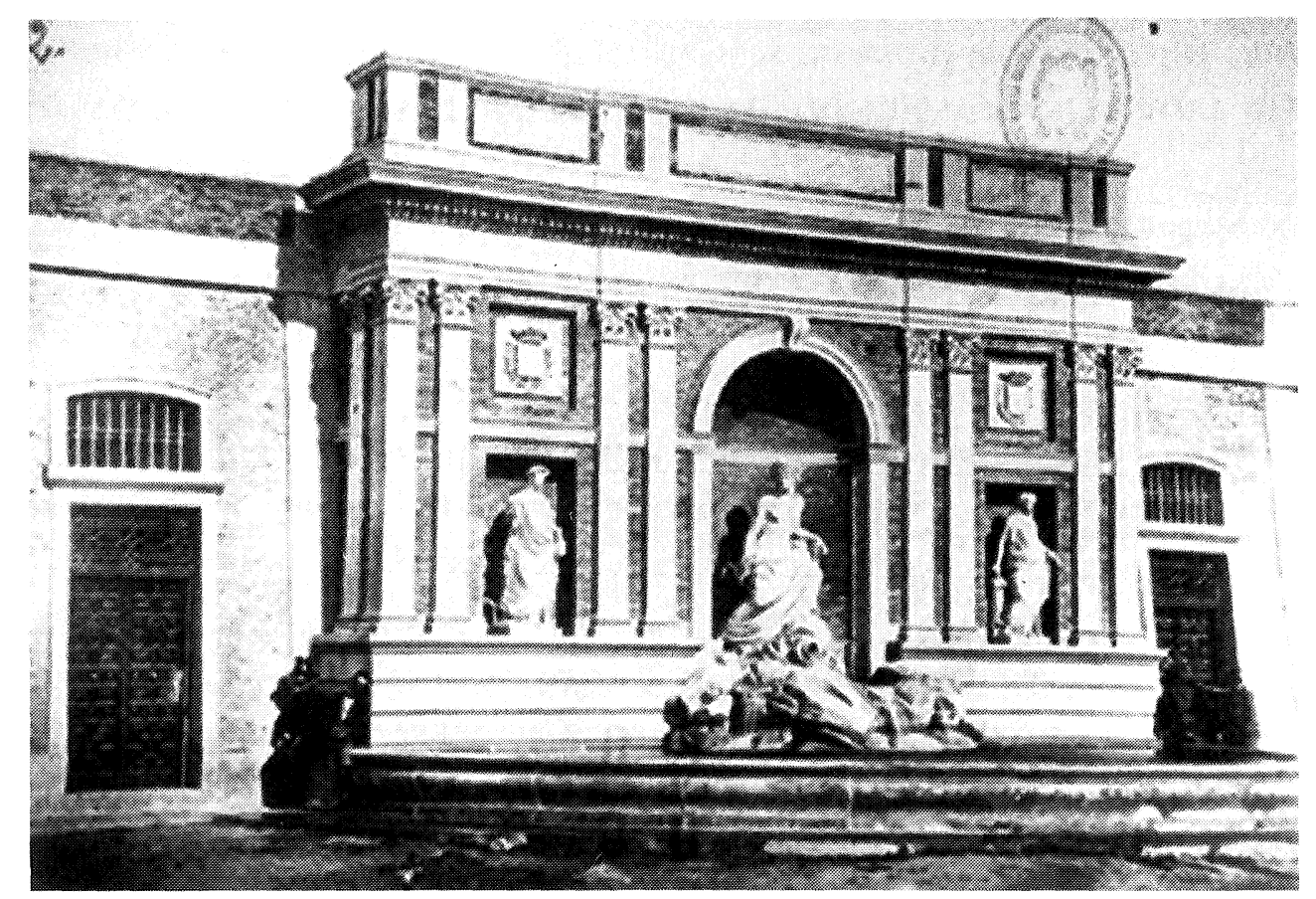

Portada del primer Depósito, o Menor, inaugurado por Isabel II el 24 de junio de 1858. 
Para la ejecución de las obras hubo que movilizar a gran número de operarios y levantar las casetas en donde alojarlos y los almacenes para el material utilizado. El mayor contingente de la mano de obra fue el de 1.500 presidiarios, en su mayoría carlistas. A ellos y a los soldados que los vigilaban hay que añadir 200 obreros libres, los capataces y sobrestantes, 400 bestias de carga y 4 bombas de vapor, amén de un sinnúmero de carros y carretillas.

El tema de la utilización de presidiarios obligados a trabajos forzados preocupó a los ingenieros. En el primer número de la Revista de Obras Públicas, en 1853, apareció un artículo de Lucio del Valle acerca de los beneficios de la mano de obra cautiva y de su idea revolucionaria de utilizar los reclusos en tareas superiores al movimiento de tierras, encargándoles las obras de fábrica, de manera que así se obtenían ventajas económicas regulando los salarios de los obreros y también, con la experiencia adquirida con los años, se lograba que fuesen hábiles mamposteros y carpinteros tan competentes como los profesionales. En un número posterior de la misma revista, el Ingeniero Ramón del Pino vuelve a tratar la cuestión desde el punto de vista de hacer menos duras las condiciones de vida de los penados. Indudablemente la disciplina y los problemas planteados a lo largo de siete años que duraron los trabajos, interrumpidos sólo por inundaciones y riadas y momentáneamente por la revolución de 1854, constituyen la pequeña historia de la construcción de tan colosal empresa. Únicamente hay que señalar la epidemia de cólera que en 1856 se extendió desde Torrelaguna hasta la capital de España, «infundiendo un pánico terror en los diferentes pueblos, causando en ellos los mayores estragos, y alejando finalmente de los trabajos a los operarios que desde provincias lejanas habían vuelto a concurrir», tal como informa en una comunicación dirigida al Presidente del Consejo de Administración, el ingeniero Lucio del Valle en un momento en que era indispensable «la concurrencia de brazos, caballerías y carros» antes de «las continuas y copiosas lluvias que sobrevienen a principios del invierno». Las duras condiciones climáticas de la Sierra afectaron precisamente la salud de Lucio del Valle, el cual acabadas las obras del Canal sufrió achaques de reumatismo. Las únicas licencias de su vida profesional fueron las que pidió para seguir curas termales en los balnearios de Viesgo en Santander, Vichy en Francia y Aix-les-Bains en Savoya.

Una imagen vale por mil documentos escritos. Las descoloridas fotografías del siglo XIX nos proporcionan hoy datos inapreciables sobre la época. El álbum Vistas de la presa y demás obras del Canal de Isabel II, que se conserva en la Biblioteca Nacional de Madrid, del fotógrafo inglés Charles Clifford, nos ahorra el tener que hacer aquí la descripción por- 


\section{Madrid y el Canal de Isabel II}

menorizada de los trabajos de construcción de tan tamaña obra. Clifford, que se instaló en Madrid en 1852, en tanto que fotógrafo de la Real Casa, fue autor de una serie de «recuerdos» o reportajes de los viajes que Isabel II hizo a las diferentes provincias españolas, con el fin de conocer a sus súbditos y a la vez que éstos conociesen a su soberana. Su trabajo era el de un cronista gráfico de la monarquía que, en ciertos aspectos, quería mostrarse como garante de la modernidad. La instrumentalización propagandística de las imágenes fotográficas de las Obras Públicas era para la Corona muy importante ya que por medio de ellas se podía constatar los adelantos materiales que se estaban llevando a cabo en el territorio nacional. A este propósito no está de más señalar que el fotógrafo, de acuerdo con las técnicas y las ideas estéticas de su tiempo, manipulaba las placas fotográficas además de hacer que los personajes que figuraban en las tomas, estuviesen colocados como si actuasen en un escenario teatral, formando una composición pictórica o un grupo estatuario. La escala monumental de las construcciones y las estudiadas poses de las figuras humanas, al igual que la descarnada y áspera belleza del paisaje de la Sierra, antes desierta, hacen que estas fotografías de Clifford resulten fascinantes, sobrepasando el mero interés documental.

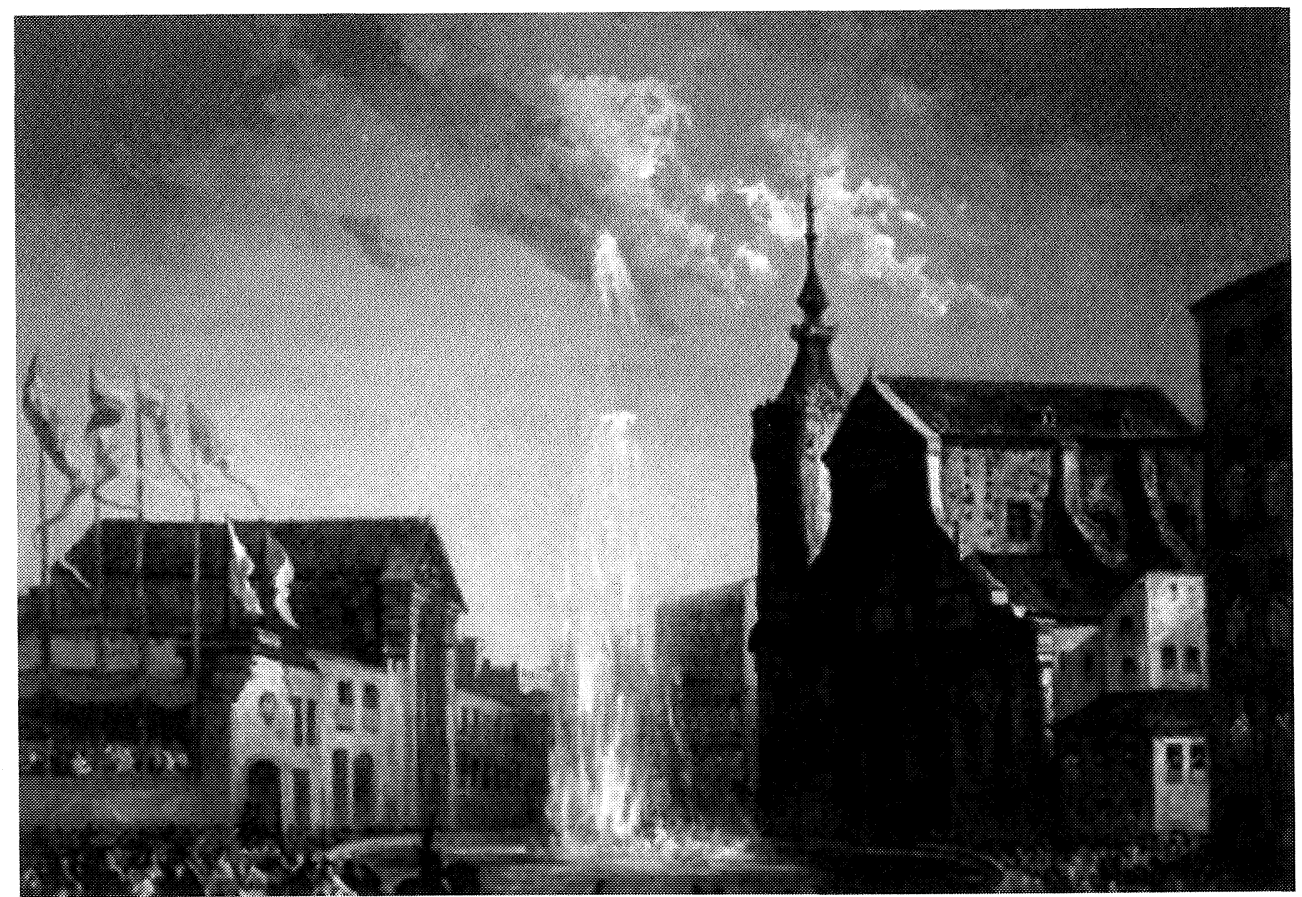

La traída de aguas de Lozoya, 1858. Eugenio Lucas Velázquez. Colección particular, Madrid. 
En el volumen que en el año 1988 el Canal de Isabel II publicó, con la reproducción de todas las fotografías de Clifford acompañadas de comentarios de conocidos escritores actuales, queremos destacar aquí el que José Antonio Gabriel y Galán hace de una vista del Pontón de la Oliva. En la imagen tomada desde lo alto, se ve en el fondo del barranco, al pie del enorme muro de la presa, una multitud de "trabajadores-hormiga» que, bajo la vigilancia de los guardianes y capataces, se afanan subiendo y bajando por escarpados senderos y pequeñas escalerillas. El hervidero de esta muchedumbre al escritor le recuerda las películas de Cecil B. de Mille. En otro comentario, el cineasta Juan Antonio Bardem, a propósito de lo «faraónico» de las obras del canal, menciona la Gran Muralla de China, el Valle de los Reyes, el Canal de Panamá y el Valle de los Caídos. También, ante la esclavitud de los trabajos forzados trae a la memoria del lector que, en 1848, se había publicado El Manifiesto Comunista, texto que es seguro que aún no había llegado, pese a ser reciente, a las manos de los trabajadores del Canal madrileño. Particular interés ofrece la fotografía de la Caserna del Presidio. Se trata de un edificio horizontal de una sola planta, con capacidad de 2.000 plazas de hospedería, construido en lo alto de la ladera del Pontón del Olivo, para el alojamiento de los presos y obreros del Canal. Sobre el tejado se ve el gran palomar para las palomas mensajeras que eran el principal Correo entre la obra y Madrid. En la fotografía vemos en la explanada que había delante de esta singular posada a los soldados que armados y en estricta formación pasan lista a los trabajadores colocados ordenadamente en fila.

Aparte de las fotografías, importantes para el estudio de las técnicas ingenieriles de la época, hay que insistir en el carácter pictórico, y a veces amable de las mismas. Muy gratas son las que muestran, junto a los acueductos, a elegantes señoras con sombrillas. Sin duda son las esposas de los ingenieros que han venido en calesa para visitar las obras que dirigen sus maridos. Los varones jóvenes, con su distinguido atuendo de campo y sombreros de ala ancha, a veces parecen personajes de las películas del oeste o de la Guerra de Secesión norteamericana. Para subrayar el carácter pictórico de las fotografias de Clifford fijémonos en la que, al pie del puente-acueducto de la Sima hay dos personajes bien trajeados y de espaldas que miran hacia lo alto de la construcción. Uno de ellos levanta el bastón indicando algo que le llama la atención de la fábrica y explica a su interlocutor. Su postura es idéntica a las figuras que Velázquez pinta en una de sus pequeñas vistas del Jardín de la Villa Médicis en Roma, cuadros que se conservan en el Museo del Prado de Madrid.

La solemne ceremonia de la colocación de la primera piedra del Canal de Isabel II tuvo lugar en donde se levantaría la presa del Pontón de la 


\section{Madrid y el Canal de Isabel II}

Oliva, el día II de agosto de 1851. El Rey consorte don Francisco de Asís, acompañado del Cardenal de Toledo, el Jefe del Gobierno don Juan Bravo Murillo con todos sus ministros, el Alcalde de Madrid y un séquito de dignatarios salieron del Palacio Real a las tres de la madrugada con el fin de llegar con tiempo fresco a la sierra. Las gentes circunvecinas de la comarca, con sus respectivos alcaldes, acudieron a ver un acto que tenía tanta trascendencia. Tras los disparos de barrenos a modo de salvas y tras oírse la Marcha Real ejecutada por la banda militar en el sitio del cruce en donde se construiría la presa, el rey, en nombre de la reina, colocó una caja de zinc con la Constitución vigente, varias monedas de oro, plata y cobre acuñadas en el año y un acta inaugural de la ceremonia. A continuación el rey recibió, en una tienda de campaña debidamente montada, los respetos de las autoridades locales y se dio un banquete en el cual la única bebida fue el agua del Lozoya.

La arquitectura de la presa del Pontón de la Oliva y de las construcciones del Canal a lo largo de todo su recorrido son un ejemplo del arte de edificar de los ingenieros de la época, todavía deudores del neoclasicismo. Su excelente manejo de la estereotomía, la mampostería, el ladrillo y los materiales tradicionales, unido a la sobriedad estilística y al rigor estructural de las formas hacen que sean obras modélicas en su género. Todas tienen el mismo sello y son fácilmente reconocibles, como salidas de los manuales de construcción de después de J. N. L. Durand, en los que se homologan las composiciones y se sistematizan las tipologías arquitectónicas. En la actualidad resultan paradigmáticas de un momento a la vez que el resultado de la manera de construir que desde la época romana se perfeccionó hasta mediados del siglo XIX, en el cual, con la aplicación de nuevos materiales -el hierro, el cristal y el hormigón armado-, utilizados por los ingenieros, revolucionaron el arte de edificar. En la construcción del Canal, para trabajar la piedra y los materiales tradicionales todavía se empleaban las herramientas y los utensilios que durante siglos habían servido a los canteros y albañiles que hacían aparejos de probada experiencia y los zapadores y peones de carreteras y trabajos de desmontes. Es interesante ver cómo en la Exposición Agrícola de 1857 en Madrid, según se refiere en el Boletín Oficial del Ministerio de aquel año (pág. 135), se enumera lo que «el presidio del Canal de Isabel II ha expuesto: legonas de pala y de gancho, zapapicos de cantera, martillo, fijas, palaustres, martinillas, macetas de cantero, trinchantes de idem, serretones, zaranda de hierro, cadena de compuertas, maromas de esparto de varios gruesos, madejas de tomiza, madejas de filete, maromas, tiros y apretadores de cáñamo de varios gruesos, ovillos de bramante, madejas de lo mismo, albardas, cinchas, ataharres, yugo, fronta- 
les, serones, esportones, cubierta de albarda, aguaderas, criba de esparto, espuertas hoceras y terreras, cabo de pleita, barriles, atalaje completo para carros, sarrieta y cerraduras». Vocabulario riquísimo que viene a ser complemento de tratados tales el Arte de Albañilena, de Juan de Villanueva, publicado por el Arquitecto Pedro Zengotita Vengoa, en 1827, Observaciones sobre la práctica del Arte de edificar, por el Arquitecto Manuel Fornés y Gurrea, en 1844, o el Código y manual de construcción, conservación y mejora, administración y policia de los caminos vecinales..., por el Coronel Capitán de Artillería y Oficial del Ministerio de Comercio, Instrucción y Obras Públicas Ignacio de Castilla, publicado en 1848.

Las obras del Canal, por la monumentalidad, la fortaleza y la perfección de sus fábricas, desde un primer momento despertaron la admiración de los profesionales de la construcción. Un testimonio fehaciente es el del Ingeniero, Matemático, Político y Dramaturgo, Premio Nobel de Literatura, José Echegaray. Al final de su vida, cuando escribió sus $R e-$ cuerdos (Madrid Científico, 1912) rememoraba cómo, en su juventud, siendo estudiante de la Escuela de Caminos, en los días de fiesta alquilaba un caballo para, en trote corto, ir a ver las obras del Canal de su amigo Morer. Echegaray, que sentía gran admiración por Lucio del Valle -por su «buen gusto» y por ser un ingeniero que en su época no tenía rival «para obras de construcción sólida... como no lo tenía por su entusiasmo por el Cuerpo de Caminos»-, consideraba que la presa del Pontón de la Oliva era una obra maestra de la arquitectura hidráulica. El Premio Nobel español, al visitar Gibraltar nos cuenta: «recorrí en los tres días todo el Peñón y en lo que me fijé, por aficiones del oficio, fue en la mampostería de las fortificaciones. Eran soberbias; pero las había aún mejores en el Canal de Isabel II. Como las mamposterías de la ladera de Patones, no he visto ningunas. Parece imposible que un muro de mampostería liso y sin adornos, pueda tener rasgos estéticos: pues los tiene, gracias al genio artístico de don Lucio del Valle. Y aquel acueducto de las Cuevas que yo vi construir, y casi vi proyectar, es el non plus ultra de la sencillez y la elegancia; al menos como modelo de elegancia y de sencillez lo recuerdo". La descripción que Echegaray hace del puente-acueducto de las Cuevas es más bien una loa, una alabanza de la ingeniería en estado puro. Este acueducto, que en un hondo y estrecho barranco, se eleva con una «sola y ligerísima pila», de la cual «sin cornisa, capitel ni accidente alguno de arquitectura» arrancan dos arcos de distinto radio, es una obra de gran belleza. Echegaray prácticamente la compara a una «palmera de piedra, de tronco ligerísimo y elevado, con las palmas de una y otra parte desigualmente encorvadas». El elogio de una construcción sin moldu- 
ras y adornos que, desnuda de ornamentación, se vale por sí misma, «por la belleza, noble, pura y elegante de la línea» es muy moderna y anticipadora de la estética funcional y racionalista de las vanguardias artísticas. Echegaray coincide en esta apreciación con las ideas del Ingeniero de Caminos Fernando García Arenal, el cual, en una disertación en el Fomento de las Artes sobre las Relaciones entre el Arte y la Industria, publicado en 1881, defendió la belleza funcional de las obras de ingeniería frente al criterio de los que, como Pablo Alzola, eran partidarios de la utilización de determinados materiales considerados nobles y de ornamentos decorativos para así dignificar las construcciones de tipo utilitario, en especial las urbanas.

La revolución de 1854, «la Vicalvarada», hizo que creciese el temor de la paralización de las obras del Canal. La visita a la Sierra del Ministro de Fomento, Luxán, para ver cuál era el estado de los trabajos, dio un nuevo impulso a la avanzada realización del Pontón de la Oliva y las conducciones de agua hasta Madrid. Ahora bien, en el otoño del año 1854, un inesperado contratiempo vino a perturbar el normal transcurso de las obras. Tal como relata Lucio del Valle en su Memoria sobre las filtraciones del Lozoya cerca del Pontón de la Oliva y medios para cortarlas, publicado en 1857, en la margen derecha del río, a corta distancia de la presa, se formó «un espantoso hervidero y tan abundante, que no solamente absorbía toda el agua que el Lozoya traía al embalse, sino que el nivel de éste empezó a bajar de manera notable». Del suceso se hicieron eco los periódicos madrileños, El Porvernir, el Occidente y El Correo Universal, que acusaban a los ingenieros de dilapidar inútilmente los millones del erario público. Puestos éstos a atajar las pérdidas del embalse, a causa de la roca permeable de sus cimientos, lograron, no sin dificultades, el rematar con éxito la obra. Desde el punto de vista científico hay que saber que cuando se emprendió la construcción del Canal los conocimientos geológicos de la Sierra madrileña eran aún muy rudimentarios. El libro de Casiano del Pozo, Descripción física y geográfica de la provincia de $\mathrm{Ma}$ drid, data de 1864. Superados dichosamente estos obstáculos, dos años antes de la inauguración Oficial del Canal, el día 29 de noviembre de 1856, de nuevo bajo un gobierno moderado, se procedió a la prueba del primer tramo ya construido. Para ello se desplazaron hasta la presa el General Narváez, a la sazón Presidente del Consejo de Ministros y una comitiva en la que figuraban el Ministro de Fomento, Claudio Moyano, célebre por ser quien promulgó, en el mismo año, la Ley de Instrucción Pública, creadora de los Institutos de Segunda Enseñanza y de una serie de normas con las que se rigió, hasta el siglo XX, la vida académica española. También iba en la comitiva el Director General de Obras Públi- 


\section{Antonio Bonet Correa}

cas, Celestino del Piélago. Después de pronunciar una arenga Lucio del Valle, el General Narváez puso en marcha los mecanismos de las compuertas dando paso al agua que, a borbotones, inundó la presa. Acto seguido las autoridades se embarcaron en botes para recorrer el «extenso lago». En prueba de agradecimiento a los que habían contribuido a la realización de tan importante obra, el primer ministro concedió indultos y rebajas de las penas a los confinados que se habían distinguido en los duros trabajos llevados a cabo. Al día siguiente, se inspeccionaron los sifones de Malcuerta y Morenilla, acabándose la feliz verificación del buen estado de las obras con un almuerzo servido en la casa del guarda del acueducto de la Sima.

De todas las construcciones del Canal de Isabel II, sin duda alguna la más sorprendente por su tamaño y perfección estructural es el Depósito de agua que hasta el presente ha estado oculto a los ojos de los madrileños. Construido en el antiguo Campo de los Guardias, una gran explanada situada en los terrenos que desde 1850 servían de lugar de ejecución de los reos condenados a muerte, y que hoy constituye el espacio

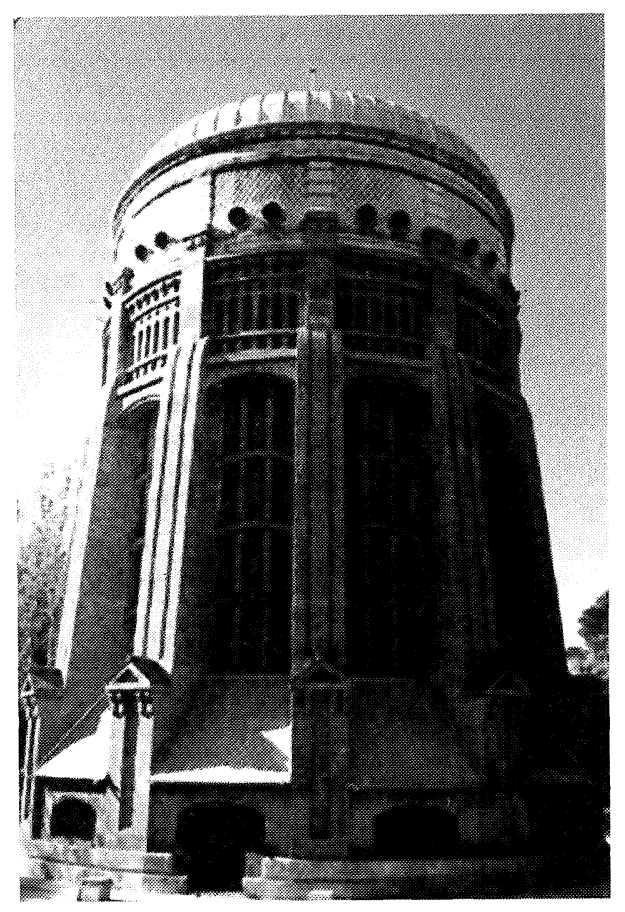

Vista actual del cuarto depósito, el primer elevado, situado en la calle Santa Engracia (Madrid). urbano delimitado por las calles Bravo Murillo y Santa Engracia, su fábrica está soterrada de forma que para los viandantes su exterior no es más que un muro liso sobre el cual hay una superficie verde sin arbolado. Únicamente en la calle Bravo Murillo hay una fuente que ha estado hasta hoy sin agua que, adosada al muro, con su arquitectura de sencillo orden dórico, está adornada con tres estatuas que simbolizan el río Lozoya, la Agricultura y la Industria, obras respectivamente de los escultores Sabino Medina, Andrés Rodríguez y José Pagniucci. De estilo neoclásico tardío, pero con áurea romántica, esta fuente popularmente conocida antaño como «fuente de los patos» por los dos cisnes que fueron agregados posteriormente y luego eliminados, evoca, aunque con sosiego, el esquema de la romana barroca Fontana de Trevi. Signo ex- 


\section{Madrid y el Canal de Isabel II}

terno del caudal que encerraba el interior -junto con la vecina estatua en bronce de Bravo Murillo, de Miguel Ángel Trilles que, en 1902 se colocó en la glorieta de Quevedo hasta que, en 1961, se trasladó al lugar actual-, la fuente del primer Depósito es un monumento figurativo y alegórico de los beneficios del agua, generadora de salud, riqueza y vida.

El interior del primitivo Depósito que ha albergado la exposición Agua y Ciudad: detrás del grifo, con la que el Canal de Isabel II celebró el 150 aniversario del comienzo de las obras que hicieron que el agua del Lozoya llegase a Madrid, es verdaderamente monumental. De planta cuadrangular, es un rectángulo de 125 de longitud por 86 metros de latitud, con 252 pilares de sección rectangular sobre los que voltean II hileras paralelas de arcos de medio punto y bóvedas baídas de ladrillo. Este interior ciego de luces es impresionante y por la repetición, sin solución de continuidad, de sus soportes, produce una sensación de infinito similar a la que se recibe dentro de la musulmana Mezquita de Córdoba. Es algo así como si el espectador estuviese en una Galería de Espejos. La solidez y la sobriedad constituyen su esencial carácter arquitectónico. Su tipología es la de las cisternas romanas. Cuando en pleno uso de sus funciones estaba inundado, quedando sumergida la estructura de su construcción, el silencio y la oscuridad debían ser extraordinarias. Penetrar en su silente y cerrado espacio tenía que ser como descender a una caverna misteriosa, a un antro en el cual reinase la noche cerrada y la soledad absoluta.

La inauguración del Canal de Isabel II el día 24 de junio de 1958, la víspera de la noche de San Juan Bautista, tuvo que ser emocionante para la reina y sus súbditos. La ceremonia comenzó con la llegada del agua al Depósito y acabó con una auténtica verbena festiva. La ciudad estaba engalanada con arcos de triunfo de enramadas, banderas y gallardetes para el recorrido de la reina que, acompañada de una numerosa comitiva de personalidades, llegó al Depósito aclamada por el pueblo. A las seis en punto de la tarde, según relata el Acta de la Presidencia de Ministros, el Ingeniero-Director del Canal, Lucio del Valle, dispuso que se levantasen las compuertas de la Casa-Partidor. "A los pocos instantes se precipitó el agua por la escalera de la entrada, formando una violenta cascada.» Según las reseñas publicadas en los periódicos «un pavoroso estruendo» se oyó de manera atronadora. Tres vivas a la reina «repetidos con el mayor entusiasmo resonaron entonces por las inmensas bóvedas del Depósito». Una serie de salvas de artillería y un repique general de campanas anunciaron al pueblo de Madrid el advenimiento acuífero tan ansiado. Fue entonces cuando el Cardenal Arzobispo de Toledo, revestido de la mitra y las magníficas vestiduras sacerdotales, «en medio del más profundo y religioso recogimiento», de los presentes, bendijo las aguas que en- 
traban en el Depósito y coros «de ambos sexos entonaron un himno alusivo al objeto». La reina tenía lágrimas en los ojos. El Presidente del Consejo del Canal, el Marqués del Socorro, pronunció un discurso en el cual proclamaba que, gracias a las Obras Públicas «la ciencia vence los obstáculos de la naturaleza" y procura la felicidad de las naciones. Acto seguido el Ministro de Fomento, tras recordar al primer ingeniero del canal, el fallecido José García Otero, hizo el elogio de Lucio del Valle «que vio al lado de aquel, asentar la primera piedra, se encargó de esta obra secular, la continuó con todo el fuego del genio y de la fe y hoy presenta a V.M. coronada de flores, como la Virgen que va a desposarse en medio de una inmensa concurrencia». No hay que olvidar que entonces estaba España en pleno romanticismo y que el ministro empleaba metáforas e imágenes inspiradas en la lírica de la época. Al dirigirse a la reina, le dice que «si el jefe de una antigua República (se refería al Dogo de Venecia) se desposaba con el mar puede también hoy decirse que V.M. lo hace con este lago que encierra bajo sus bóvedas el consuelo, la salud, la belleza y la comodidad de la Monarquía; el verdor, la frescura y la fertilidad de las ardientes arenas de sus campos».

El periódico La Época, al reseñar la «augusta e inolvidable ceremonia», publicó unas inspiradas estrofas «de uno de nuestros más distinguidos poetas» que ante el torrente que llenaba el Depósito, escribía:

«Corrred! clamó Isabela:
Y sumisas al regio poderio
De la tierra horadando las entrañas
corren las aguas de copioso río
La Corte a fecundar de las Españas
Nuncio de tal portento
La náyade más bella se adelanta
con presurosa planta:
Rompe la cárcel dura
Y alzase al firmamento
Del iris reflejando la hermosura...».

Y aludiendo al sol, a la envidia de Neptuno y los «regios muros de la coronada villa de Madrid, cantaba el prodigio y las maravillas de una obra colosal y sobrehumana.

La ceremonia de la inauguración no se acabó al llenar el Depósito. La reina, su marido y el Príncipe de Asturias, el futuro Alfonso XII, en brazos de su nodriza, se trasladaron hasta el solar de Monteleón en la Calle Ancha de San Bernardo, a la altura de la iglesia de Montserrat. Allí se había dispuesto una tribuna para asistir a la apertura de una fuente que, 
con su cascada y surtidor se había instalado provisionalmente con el fin de que el pueblo de Madrid viese la llegada del agua que tantos beneficios reportaría a la capital de España. A las ocho y media de la tarde de tan radiante día, la reina movió la clavija que hizo que surgiese un chorro de agua tan potente que alcanzó 90 pies de altura, es decir 30 metros, superando el alzado de las casas del entorno. Gritos de júbilo y sombreros al aire estallaron en la multitud que asistía al acto. Tras el clamor popular de admiración leyeron poemas y loas, cantándose un himno compuesto para la ocasión, en el que se decía:

\author{
«Honor, gloria a la Ciencia, \\ palanca irresistible \\ al genio creador. \\ Por él Lozoya altivo \\ se arranca de su asiento \\ $y$ eleva al firmamento \\ su inmenso surtidor».
}

No se sabe a ciencia cierta si fue entonces cuando Posada Herrera le dijo a la reina «Señora hemos tenido la suerte de ver un río poniéndose de pie» o si fue más tarde, al colocarse la fuente del surtidor en la Puerta del Sol, cuando el autor de folletines Manuel Fernández y González dijo «Milagro de la civilización este poner los ríos en pie». Tampoco es muy seguro que Juan Bravo Murillo, el cual a causa de la política adversa del momento no fue invitado a la inauguración, confundido entre el público que asistía al acto en la calle, dijese «iYa podemos lavarnos todos!».

Al día siguiente la Reina dió en el Palacio Real un banquete a los ingenieros e impuso a Lucio del Valle la Gran Cruz de la Orden de Carlos III, diciéndole: «Valle: si Carlos III viviese colocaría en tu pecho la cruz de la Orden que instituyó para premiar la virtud y el mérito. A su nieta cabe la satisfacción de ponértela, la de apreciar tu talento». Para recordar perpetuamente la ceremonia de inauguración se acuñaron medallas. Lo que no hubo, por impedimentos burocráticos fue la serenata que se pensó dar al ingeniero que había tenido la constancia y el tesón necesario para realizar la ingente obra. Lo que sí nos ha quedado, además de las descripciones encomiásticas de los periódicos, son las imágenes gráficas que representan el surtidor en la calle Ancha de San Bernardo. Eugenio Lucas pintó un magnífico lienzo en el cual se ve la tribuna regia, la iglesia de Montserrat y la variopinta multitud que asistió al acto. Además, de varios grabados con el mismo tema se conserva una fotografía anónima del surtidor con un primer plano en el cual hay unos ele- 
gantes caballeros con su chistera. En el Museo Universal se publicó un grabado con una vista del surtidor bajo la luz de la luna llena de San Juan. De lo que no queda duda es de que la jornada, como dijo la prensa, había sido «uno de los acontecimientos más notables» de la época, digno de figurar en los Anales de la Historia de Madrid.

En 1858 Madrid tenía una población de 240.000 habitantes a los cuales habría que abastecer de agua. La red de distribución del caudal del Canal en la ciudad, diseñada por Morer en 1855 tenía una serie de conducciones subterráneas adaptadas a la topografía, un tanto quebrada, de la capital. A partir del Depósito de Chamberí partían dos arterias principales que, unidas a una transversal, formaban una gran $\mathrm{A}$, con sus consiguientes ramificaciones. La primera arteria seguía la Calle Ancha de San Bernardo, la plaza de Santo Domingo, la Costanilla de los Ángeles, las calles de las Fuentes y la de Ciudad Rodrigo, la Plaza Mayor y la calle de Toledo hasta la Puerta del mismo nombre. La segunda arteria discurría por las calles Fuencarral y Montera, Puerta del Sol y las calles Carretas y Atocha hasta Amor de Dios. La arteria transversal iba desde la calle Bailén hasta Neptuno pasando por la Calle Mayor y la Carrera de San Jerónimo. Las ocultas tuberías, con sus múltiples ramales, en su representación cartográfica, forman una estructura reticular similar a los esquemas de las láminas histológicas del sistema humano dibujadas por Ramón y Cajal. Para la utilización de las aguas sobrantes se iniciaron las obras de tres acequias Norte, Este y Sur, los llamados «canalillos», para regar las huertas de los alrededores de la capital. El ingeniero Juan Rivera, en su Memoria sobre el Riego de los Campos de Madrid, describe los beneficios que estos canales al aire libre,-que a partir de la Casa del Partidor, en la cual se dividen las aguas que llegan a Madrid-, reportarían la fertilidad y el frescor a la árida ciudad mesetaria. La idea de convertir las afueras de la capital de España en un vergel formó parte de la gran ilusión de un tipo de madrileño ilustrado y progresista, amante de la naturaleza. Pero el abandono y el mal aprovechamiento de estas acequias hicieron que el Madrid verde no fuese más que un sueño, sólo cumplido en algunos jardines de los chalets de la Ciudad Lineal o de las pequeñas colonias de casas unifamiliares. «El Canalillo», que próximo a la Residencia de Estudiantes y sobre el cual escribió Juan Ramón Jiménez en "La Colina de los chopos», se conservó en el siglo XX hasta poco después de la Guerra Civil, fue un paisaje familiar y lírico para los poetas y los intelectuales de la generación del 27.

La primera casa madrileña en la que se instaló el agua corriente fue la del Marqués de Bendaña. Al principio tener a domicilio el agua que salía de un grifo era un lujo aristocrático, propio de las mansiones de los 
nobles y la gente acomodada. Pero pronto se fue generalizando el contar con tan moderno adelanto, aunque en los barrios más pobres las familias se suministraban del agua de una fuente colocada en el patio. Como en todo tiempo ha ocurrido con las novedades que producen la alarma de los usuarios los periódicos de la época advertían a las amas de casa del peligro que se corría si se olvidaba de cerrar el grifo: el piso se inundaba y podía calar con grave perjuicio en el techo del vecino de abajo. A la vez que se multiplicaban las instalaciones particulares de agua se colocaron en las calles bocas de riego para la limpieza de las mismas y para apagar el fuego y de paso ser utilizadas en caso de incendios de los inmuebles. En una caricatura publicada, en 1862, por el Museo Universal, se retrata una escena muy utilizada más tarde como «gag» en las películas mudas de cine cómico: un novato empleado del servicio municipal de limpieza, incapaz de dominar la tromba de agua que sale de la manga de riego, rocía a los desprevenidos paseantes proyectándoles violentamente contra el muro de una casa.

A partir de su inauguración la historia del Canal de Isabel II puede dividirse en varias épocas significativas. Las obras de ampliación, de construcción de nuevas presas y nuevos depósitos, de depuradoras de agua y la modernización de sus instalaciones constituye un capítulo de enorme interés desde muchos puntos de vista, tanto por las construcciones ingenieriles como por la organización y los beneficios de tan importante servicio público. Para Severino Bello Poeyusen, ingeniero jefe del Canal, -que publicó el Informe o Libro-catálogo de la muestra que el Canal hizo en la Exposición Iberoamericana de Sevilla en 1929_, la historia del Canal se dividía en tres períodos: el primero de 1851 a 1866, el segundo de 1867 a 1907 y el tercero de 1907 a 1929 . Con la perspectiva que ahora tenemos nosotros se pueden añadir otros dos nuevos períodos, el que va desde 1939 hasta el último a partir de la década de los ochenta de fines del siglo XX hasta nuestros días en los cuales el Canal ha entrado en una nueva etapa o era post-técnica.

En el año 1865 el Canal, ante la creciente demanda de agua y para resolver los problemas que planteaba en época de estiaje el menor caudal de agua almacenada, construyó un nuevo Depósito. Situado entre las calles Bravo Murillo y Santa Engracia, enfrente del primer Depósito, en los terrenos que eran propiedad del Estado, este segundo Depósito tenía la capacidad de 180.000 litros de agua. Con tal caudal se aseguraba el abastecimiento de Madrid durante veinte días en caso de haber avería en la traída desde la Sierra. De gran tamaño, tenía una planta rectangular de 207 X I37 metros por lado. Su fábrica, —con 1.040 pilares cuadrados con basas de piedra y fuste de ladrillo enfoscado que forman hileras de arcos 
de medio punto cubiertas de bóvedas de cañón rebajado-, pertenece al tipo de construcción industrial de la época. Al exterior este Depósito, al igual que el primitivo, está formado por una superficie de verde pradería. En la dos esquinas a la calle Bravo Murillo se levantan sobre este tapiz vegetal dos pequeños edículos o casetas para elementos de maniobra de compuertas y válvulas de entrada y salida reguladoras. Su arquitectura de piedra y ladrillo tiene, por su sobriedad, ese sello de neoclasicismo tardío propio de las obras ingenieriles. De gran prestancia es la escalinata de doble tiro que forma una pequeña fachada del Depósito en la parte central del muro de la calle Bravo Murillo. Con sus lisos y severos paramentos y su frontón triangular, rompe la línea horizontal y monótona de la calle, proporcionando monumentalidad al conjunto.

La construcción de una nueva presa, aguas arriba del Pontón de la Oliva, vino a reforzar el caudal de agua del Canal del Lozoya. De 1869 a 1879 se levantó, con una técnica novedosa en la edificación de embalses, la presa del Villar. Obra de los ingenieros José Morer y Elceario Boix, la primera piedra fue puesta por el ministro de Fomento José Echegaray quien, como ya dijimos anteriormente, además de ingeniero de caminos, era amigo de Morer. Con esta obra la revolución «La Gloriosa», que en 1868 había destronado a Isabel II, continuaba la empresa de dotar a Madrid de agua. La presa del Villar que regulaba las aguas del Lozoya embalsando las sobrantes del deshielo en la primavera con el fin de utilizarlas durante el estiaje, en tanto que obra de ingeniería es una realización en piedra de granito, de gran interés histórico ya que fue la primera presa de arco de gravedad que se construyó en Europa. Obra maestra que se adelantó en treinta años a las que luego se construirían en el mundo, tiene una sección curva de 130 metros de longitud por 55 metros de altura. Todavía en funcionamiento, dio origen al Canal del Villar. Impresionantes son las fotografías de cuando todavía estaba vacía. Con su lisa muralla cóncava en talud y la torre de toma central, punteada con vanos rectangulares, parece una fortaleza medieval capaz de resistir los mayores embates. Vista en la actualidad plena de agua, forma un lago al que coronan las cimas nevadas una parte del año del espléndido paisaje de la sierra, cantada a finales de la Edad Media por el marqués de Santillana.

A principios del siglo XX, según iba creciendo Madrid y aumentaba su índice demográfico, el Canal de Isabel II realizó nuevas obras como el canal transversal y el aprovechamiento de la energía hidráulica de la traída, con la construcción de la central hidroeléctrica de Torrelaguna. La Presa de la Parra, que empalma con el Canal Viejo, ahora Canal Bajo o el Azud del Mesto, el aprovechamiento del agua del río Guadalix y otras obras supletorias fueron completando la red cada vez más extensa del 
Canal de Isabel II. Madrid, que a principios de siglo había duplicado en número de habitantes y que de capital había pasado a ser una metrópoli moderna, cada vez necesitaba más agua para el consumo y la industria. La construcción de un tercer Depósito, con mayor capacidad que los dos anteriores, se imponía. Para su realización se escogió el terreno que todavía quedaba libre en el Campo de los Guardias, entre lo que hoy son las Avenidas de Islas Filipinas y la de San Francisco de Sales, las calles de Santander y Pablo Iglesias, cerca del Partidor de Aguas, que estaba en donde actualmente se levantan el Instituto Geográfico Nacional y el Cuartel de la Guardia Civil. Realizada ya de 1893 a 1897 la excavación general del vaso y en 1900 consolidado el subsuelo, en 1903 se contrató con el ingeniero José Eugenio Ribera la construcción de un Depósito de fábrica de hormigón armado. Ribera, —que fue el primer ingeniero que, dejando de ser funcionario, montó una empresa de contratos de obra, además de ser el autor de importantes puentes fue el introductor del hormigón armado, - proyectó un Depósito muy diáfano a base de pies derechos de sección rectangular y vigas y cubiertas planas muy ligeras. La fábrica estaba muy avanzada cuando, en el mes de abril de 1905, se derrumbó una parte de la cubierta en hora de trabajo, de forma que murieron 24 obreros y 60 sufrieron graves heridàs. La catástrofe produjo una gran conmoción y alarma en la Łiudad. Los periódicos acusaron al ingeniero de incompetencia y a las autoridades de negligencia en el control de las obras. El hundimiento alcanzó gran resonancia. La prueba es que la Condesa de Pardo Bazán, en su crónica cultural en La Ilustración Artística, se hizo eco de la noticia al tiempo que señalaba el centenario del Quijote y reseñaba el fallecimiento del escritor Don Juan Valera. En la Revista de Obras Públicas, se puede seguir paso a paso los comentarios sobre el suceso, las críticas y refutaciones que sobre el uso del hormigón armado se hicieron en la prensa diaria y en las revistas especializadas. Incluso en el extranjero interesaron las vicisitudes que condujeron a tan adverso desastre. Las revistas Le Béton Armé y Béton \& Eisen se ocuparon del asunto. El Dr. Fritz von Emperger, de Viena, hizo un informe científico detallado del asunto. Como ha constatado Miguel Aguiló, en su artículo "Ladrillo y acero", en el volumen La reconversión del Depósito Elevado, publicado por el Canal de Isabel II en 1986, el accidente no fue el único en el mundo de aquel período inicial del hormigón armado. Hans Strauss lo recuerda en su Historia de la Ingeniería Civil: «En 1982 colapsa un arco de piedra en Podol, cerca de Praga; se producen varios accidentes en los edificios de la Exposición Universal de París de 1900 y en 1906 se derrumba el hotel Zum Goldenen Bären en Basilea. Toda Europa comienza la redacción de nuevos reglamentos para el empleo de ese 


\section{Antonio Bonet Correa}

material durante los años 1903 a 1909». En España la Revista de Obras Públicas, que salió en defensa de Ribera, al reseñar la catástrofe constataba que «las grandes obras llevan consigo, por los errores inevitables de los hombres, o por causas inexplicables para su inteligencia en donde intervienen las fuerzas ciegas de la naturaleza, grandes catástrofes». Por último quien acalló las acervas críticas fue D. José Echegaray quien, sin temor a jugarse su prestigio de ingeniero hizo «prevalecer su tesis de que el hundimiento había sido provocado por una ola de calor no previsible en aquella época del año» tal como Fernando Sáenz Ridruejo nos lo recuerda en su libro Ingenieros de Caminos del siglo XIX (1990). Como el ingeniero M. Landi afirmaba en la Revista de Obras Públicas en un artículo sobre «Las verdaderas causas del hundimiento», la dilatación de los hierros «contenidos en la longitud extraordinaria de las vigas contribuyó a que éstas sufriesen una deformación tan extraordinaria que se retorcieron sobre sus mismos ejes, ocasionando el desencaje del sistema. La homogeneidad de trabazón entre las vigas y los pilares no pudo resistir a la torsión que intervino inopinadamente, sucediendo lo que no se había previsto». Lo peor es que por el momento se perjudicó a la industria y al sistema constructivo del hormigón armado en España. El tercer Depósito fue acabado en 1915 el ingiero Parrello, empleando el tipo de edificio de pilares, arquerías y bóvedas de cañón en ladrillo enfoscado, de acuerdo con los modelos de los antiguos algibes o cisternas. Fue el triunfo de lo convencional y conocido en la construcción tradicional. Sin embargo este cataclismo no fue óbice para que el cemento en el siglo XX fuese un material que revolucionó las técnicas constructivas y las formas arquitectónicas e ingenieriles a nivel mundial.

Un hito urbano esencial en el barrio de Chamberí es el Depósito elevado que se construyó de 1910 a 1912, a la orilla del segundo Depósito, en el margen izquierdo de la calle Santa Engracia cuando se va en dirección a la glorieta de Cuatro Caminos. Hoy esta zona de la ciudad está muy poblada y es de mucho tránsito. Cuando se levantó el Depósito elevado todavía su entorno apenas estaba construido. El extenso complejo de los tres primeros depósitos del Canal de Isabel II actuó como barrera de la expansión urbana de forma que existía un vacío despoblado. Después de la Guerra Civil el barrio comenzó a colmatarse y hoy forma parte del continuo urbano, incorporándose con su peculiar trama al tejido de Madrid. Es ahora cuando el Depósito elevado, que ya no funciona como tal Depósito y que, restaurado en 1986, sirve de Sala de Exposiciones de la Comunidad, ha adquirido su calidad de hito, de enseña o emblema de una zona que, por sus amplios ámbitos abiertos, ofrece un especial atractivo aquellos que no son ajenos a la arqueología industrial. La idea de la 
construcción de Depósitos elevados databa de 1898, dada la necesidad de abastecer de agua a las zonas del Ensanche y del Extrarradio, en especial en las zonas altas que, como la Ciudad Lineal de Arturo Soria, habían desbordado los límites de la ciudad. De igual forma que las líneas del tranvía y del metropolitano, las conducciones de agua iban marcando una nueva etapa del crecimiento de Madrid. Otro tanto podría decirse de los Servicios de las vías públicas y alcantarillados a cargo del ingeniero municipal Núñez Granés, el gran estudioso del extrarradio madrileño. En 1900, al iniciarse el nuevo milenio, el ingeniero Diego Martín y Montalvo redactó una Memona sobre los tres nuevos Depósitos elevados que necesitaba la ciudad, de los cuales sólo se construyó el arriba mencionado. El Ingeniero-Director del Canal, Ramón de Aguinaga, en 1913, después de afirmar que dada la topografía accidentada de Madrid y sus alrededores era mala solución el conducir a zonas elevadas «aguas rodadas», indicaba premonitoriamente que «si Madrid se ensancha en el porvenir por la parte de Chamartín sería preciso una nueva zona elevada que comprenderá un nuevo depósito». A la vez era consciente de que «al Canal se debe que Madrid se haya ensanchado y que existan tan hermosas barriadas y especialmente en las zonas altas». Esta última frase hace que recordemos los hotelitos que, como el de la novela El chalet de las Rosas, de Ramón Gómez de la Serna o los que se enseñaban en los halagueños y reductores prospectos de propaganda de La Ciudad Lineal, estaban rodeados de un precioso y florido jardín, vergel factible gracias al Canal.

El Depósito elevado, también llamado el «Vaso» por el enorme recipiente metálico que encierra en su interior, con capacidad de 1.500 metros cúbicos, servía para regular la presión del agua que abastecía el barrio de Salamanca y la zona Norte de Madrid. Su funcionamiento era posible gracias a los adelantos técnicos y el uso industrial de la electricidad. La central elevadora, con potencia de $1.400 \mathrm{CV}$, construida para hacer ascender el agua del Segundo Depósito al Depósito elevado, es un edificio de estructura basilical que, con su exenta chimenea y su sobria fábrica de ladrillo y paneles acristalados, contribuye a hacer que se magnifique la esbelta silueta del «Vaso» cuyo diseño arquitectónico es de gran belleza y cuidada realización. Torre de piedra y ladrillo, eregido para soportar el considerable peso de la gran cuba o enorme recipiente metálico, tiene la planta de un poliedro de doce lados que, en lo alto, se resuelve en un anillo circular sobre el cual se apea el zuncho que ancla el vaso. Una gran cúpula de zinc sobre un tambor corona el vertical perfil decreciente de la torre cuya base forma un talud. Hasta la altura del friso los contrafuertes están arriostados por doce arcos rebajados a manera de gran- 
des nichos que cobijan los delgados paramentos de los entrepaños que forman una retícula de machones y arquillos rebajados que, como una membrana, reciben el exterior del edificio. En el friso se abre una corona de estrechos y alargados vanos que, a manera de saeteras, introduciendo una nota de claroscuro que contrata con la rosada superficie de la totalidad. La nota plomiza del domo se remata con una semiesfera, se forma que humaniza el sentido utilitario de la Torre.

Sorprendente es el interior cilíndrico de espacio hoy diáfano al haberse suprimido las tuberías que ocupaban la parte central de la torre. No queremos aquí hacer la descripción de las escaleras al aire y de las plataformas anulares y metálicas que llevan hasta el vaso suspendido en lo alto. A Miguel Aguiló le recuerdan los grabados de Piranesi. Para la descripción del interior remitimos al lector al artículo que hemos escrito en Academia, Boletín de la Real Academia de Bellas Artes de San Fernando (n. $\left.{ }^{\circ} 64,1987\right)$, titulado «El Depósito Elevado del Canal de Isabel II en Madrid. Arquitectura, Técnica y Ciudad». Solamente señalamos que es obra del ingeniero Luis Moya Idígoras, - padre del gran arquitecto Luis Moya Blanco-, con la colaboración para la parte técnica de Ramón de Aguinaga. Obra singular dentro de su género, que huye del banal aspecto de la torre de agua, el Depósito elevado de Moya es una mezcla de modernidad y tradición. Como hemos escrito en el artículo citado «su aspecto es doble en su diseño. Por un lado tiene reminiscencias medievales, de estilo mudéjar, que hubieran sido todavía más evidentes si, como quería su autor, se hubiese recubierto el tambor de la cúpula con azulejos blancos y verdes a la manera de las torres mudéjares de Teruel, ciudad que Moya conoció en su primer destino de ingeniero del canal de Aragón. Por otro lado es el resultado de la influencia de la Secesión vienesa, movimiento arquitectónico que influyó poderosísimamente en el Madrid de la época y que Moya, sin haber viajado a Austria, conocía muy bien a través de las revistas y los libros. También es digno de ser recordado, tal como nos lo cuenta Manuel Sánchez Camargo, en su Historia de la Academia Breve de Crítica de Arte (1963) que Eugenio D’Ors, siempre preocupado por la formación estética de sus seguidores e interlocutores, en sus paseos o lecciones peripatéticas por Madrid los llevaba «a los depósitos de agua del Canal de Isabel II para hacer notar a los visitantes las características arquitectónicas y constructivas» del conjunto. Su elección es reveladora de un estado de espíritu. En el caso concreto del Depósito elevado hay que reiterar que se trata de un monumento clave, una obra única, un arquetipo, una obra y pieza maestra de un valor inestimable. Auténtico mojón urbano es todo un símbolo de la modernidad, que transciende su originario destino utilitario. A la manera de las construcciones 
metafísicas de Giorgio di Chirico, es una edificación que se incorpora a la memoria y a los sueños de los transeuntes más curiosos. La Calle de Santa Engracia actual sin la vertical torre del Depósito elevado sería una vía anodina y amorfa de la ciudad tentacular.

En el primer tercio del siglo XX Madrid, que en 1910 tenía 599.807 habitantes pasó, en 1932, a tener 952.823, se desarrolló con nuevos núcleos de expansión -La Prosperidad, La Guindalera y Ciudad Lineal- y en el centro del antiguo casco urbano experimentó una transformación arquitectónica importante. La apertura de la Gran Vía y la construcción de nuevos y espléndidos edificios bancarios y comerciales, además del Hotel Ritz (1908) y Hotel Palace (1910), son índice del progreso y auge de la capital de España, que coincide con là aparición del metropolitano, del automóvil y del cinematógrafo y un notable cambio de costumbres que afectó á todas las clases sociales. Hasta los castizos madrileños adquieren hábitos antes sólo reservados a los estratos más distinguidos de la Corte. En lo que se refiere a la higiene corporal es entonces cuando se generalizó el dotar a las casas de un cuarto de baño. Cuando Bravo Murillo pronunció la frase «ahora podremos lavarnos todos» no podía pensar que pasados los años, con el agua corriente en los pisos se llegaría a tener instalaciones tan completas para el aseo personal. En el año 1850, cuando todavía no había llegado el agua del Lozoya a Madrid, en el periódico El Fandango se podía leer en un artículo que «el baño a domicilio es un plagio de las costumbres aristocráticas. El que se baña en casa es demasiado gran señor para ir a buscar el río, el mar o la casa de baños; es preciso que la casa de baños, el mar, el río, acudan a la habitación del que se baña... La literatura satírica y costumbrista era la que se refería de manera explícita a los baños. En 1876 Ignacio Parado afirmaba que «los baños son buenos y deben usarse con frecuencia, bastando un baño semanal o quincenal para el aseo», aunque "es costumbre que tiene algunos inconvenientes: hace gastar tiempo innecesariamente y habitúa a una necesidad física que no hay que adquirir». Codina, en su Tratado completo de higiene (1880), escribía de broma en verso:

\author{
«Enjuágate cada día \\ la boca y limpia los dientes \\ con tal que no haya presentes \\ personas de austeridad \\ toma baños de limpieza \\ mayormente en verano \\ $y$ los pies también es sano \\ de vez en cuando lavar».
}


A finales del siglo XIX y principios del XX, gracias a la mayor abundancia de agua en los pisos y sobre todo a la mutación de las costumbres se transformaron radicalmente las formas de aseo. Las familias más acomodadas comenzaron a instalar inodoros de tazas cerámicas de fabricación española e higiénicos cuartos de baño en sus hogares. Atrás quedaban las mujeres de los cuadros del francés Degas que, en una palangana instalada en su alcoba, desnudas hacían en cuclillas su íntima toilette. Ahora se podía hacer abriendo el grifo para llenar la bañera como la joven que en 1895, Ramón Casas, retrata sin ropa y de espaldas, en el cuadro Preparando el baño o como la que, vestida con una bata ligera o «matinée», en el cuadro Antes del baño, entre el brillante lavabo y el vaho del calentador del agua, se prepara para meterse en el agua caliente. No hay que olvidar que en las primeras décadas del siglo XX la escritora y feminista Carmen de Burgos, Colombine, publicaba en Madrid, en su revista Friné, dirigida a las mujeres deseosas de una nueva forma de comportamiento, artículos sobre la higiene corporal cotidiana. También que en los años veinte en la prensa ilustrada se publicaban anuncios con modelos de modernos cuartos de baño completamente equipados y alicatados. Por otra parte en la sección humorística de los semanarios como Blanco y $\mathrm{Ne}$ gro no faltaban caricaturas en las cuales se ridiculiza a los nuevos ricos que no sabían utilizar tan pulcra instalación o aleluyas en las cuales se representaban las tribulaciones de aquellos a los que por falta de presión al vivir en un piso alto, no tenían más remedio que volver a usar una jofaina como en los tiempos de antaño.

En 1940 Madrid tenía 1.618.435 habitantes, pasando a tener 2.259.931 en 1960. En veinte años la ciudad había tenido un desarrollo espacial considerable acorde con el aumento demográfico. El mito del Gran Madrid sobrepasaba todas las previsiones y el ritmo acelerado del crecimiento demográfico y de la edificación era imparable. La prueba son los años que llegan hasta los nuestros cuando la ciudad cuenta con más de 5.000.000 de almas. El Canal de Isabel II supo responder a la demanda del servicio de aguas, no sólo para la capital sino también para abastecer a todas las poblaciones del área metropolitana, hoy englobadas en la Comunidad de Madrid. En materia de presas, aparte de la de Puentes Viejas, acabada en 1925 y recrecida en 1939, el Canal de Isabel II ha construido, dentro de la provincia de Madrid, 13 presas y dos azudes, 12 estaciones de tratamiento de agua, con 8.498 kilómetros de red y 65 plantas depuradoras, además de 18 depósitos reguladores, entre los cuales es de destacar el de la Plaza de Castilla, con su torre de agua o Depósito elevado. Sin enumerar las arterias de abastecimiento y la red moderna de distribución del agua a domicilio, señalemos el modernísimo sistema de 
información y control para el aprovechamiento óptimo de los recursos hidráulicos de la Comunidad de Madrid. Las Centrales automáticas de telecontrol son algo así como un cuento de magia-recuérdese la frase de Galdós del «cuento de hadas» para el usuario del Canal, sólo pendiente de si el recibo de su consumo de agua ha subido o es caro. Para el madrileño que a diario abre el grifo, probablemente el hilo del agua potable que le dispensa carece del valor mítico y sagrado de elemento purificador y bienhechor, que dispensa salud y energía. Al menos no piensa en ello. Tampoco será capaz, con una simple ojeada, de desentrañar con todo su significado la complejidad del abstracto «Esquema general de las instalaciones de abastecimiento» del Canal de Isabel II diseñado, en 1993, por Roberto Turégano. Es como un cuadro de Mondrian. En el libro de Carmen Gavira, Miradas desde la ingeniería. Redes e infraestructuras en Madrid (1996), al analizar este tablero que «incluye el telecontrol con 36 estaciones remotas, un sistema de telefonía móvil capaz de transmitir voz y datos a cualquier vehículo, la telefonía fija a través de una red de conmutación de 40 centralitas digitales, un sistema de transmisión de datos entre ordenadores de gestión...», la autora concluye diciendo que supone el paso de «la ciudad del agua oculta» a la ciudad de «las aguas inteligentes».

Para finalizar nuestra disertación sobre el Canal de Isabel II añadamos a la visión panorámica de las antiguas presas del Pontón de la Oliva y del Villar, la de El Atazar, en funcionamiento desde 1972. Es la presa más importante del sistema de abastecimiento de la Comunidad de Madrid.

Del tipo de bóveda gruesa con doble curvatura, sus 134 metros de altura y su longitud de coronación de 484 metros tiene un volumen de fábrica de 1.100 .000 metros cúbicos. Su visión, tanto a pie de obra como desde el aire es grandiosa. Construcción más conocida, por encontrarse en un lugar de obligado paso cotidiano de muchos madrileños, es el Depósito elevado de la Plaza de Castilla. Levantado en los años cuarenta, con su estructura de tipo meramente funcional, es una obra que podría calificarse de «brutalista». Su contundente silueta marca uno de los espacios urbanos más transitados de la capital de España, rivalizando con la escultura en forma de proa dedicada a Calvo Sotelo y con la arquitectura de líneas oblicuas de los dos pequeños e inclinados rascacielos de la llamada Puerta de Europa.

La celebración del 150 aniversario del inicio de las obras del Canal de Isabel Il, en 1851, hace que volviendo nuestra vista al pasado podamos hoy comprender el enorme avance que la llegada del abundante caudal de agua del Lozoya a Madrid supuso para el desarrollo de la capital de la 


\section{Antonio Bonet Correa}

monarquía española. La población no sólo pudo apagar su sed secular y crecer demográficamente sino que también pudo ensancharse con nuevos barrios fuera del antiguo recinto de su casco histórico. De una capital monárquica de mediano tamaño, en medio siglo pasó a ser una ciudad moderna, ulteriormente convertida en metrópoli. El Canal fue el sistema sanguíneo que le dio vida y que, atentó a todas las necesidades, se amplió y modernizó todas las veces que fue necesario. El estudio de su historia de siglo y medio lo confirma. En esta exposición quedan trazados los lineamientos generales de su acción en pro de la ciudad con la que se identifica íntimamente. El actual Canal, con su aplicación de las nuevas tecnologías y su gestión integral de los recursos hidráulicos de la Comunidad de Madrid, mira hacia el futuro de la capital de España, en su imparable marcha hacia la modernidad.

Nota: La versión original ilustrada de este trabajo apareció en el Catálogo correspondiente a la Exposición "AGUA Y CIUDAD detrás del grifo", editado por la FUNDACIÓN Canal de Isabel II - EDICIONES DEL ANIVERSARIO (ISBN: 84-920615-96, Depósito legal. M-27691-2001; páginas: 15-71). Con autorización del autor. 